NASA Technical Memorandum 87222

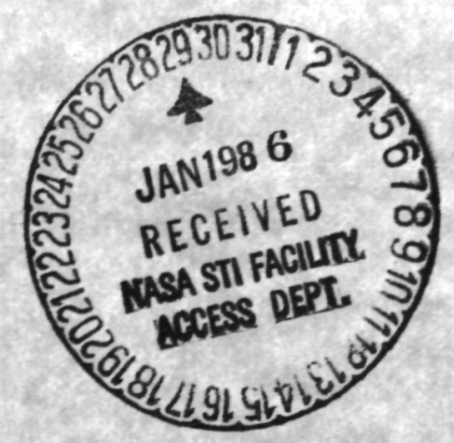

\title{
Reliability of Scanning Laser Acoustic Microscopy for Detecting Internal Voids in Structural Ceramics
}

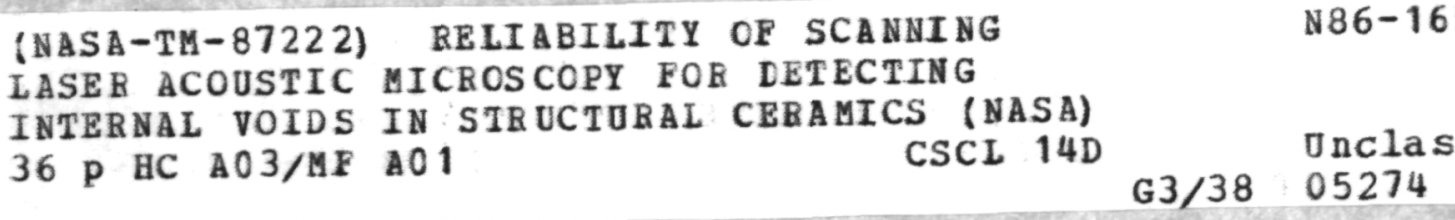

Don J. Roth and George Y. Baaklini

Lewis Research Center

Cleveland, Ohio

Prepared for the

Tenth Annual Conference on Composites and Advanced Ceramic Materials sponsored by the American Ceramic Society Cocoa Beach, Florida, January 19-22, 1986 


\title{
RELIABILITY OF SCANNING LASER ACOUSTIC MICROSCOPY FOR DETECTING
}

\author{
INTERNAL VOIDS IN STRUCTURAL CERAMICS \\ Don J. Roth and George Y. Baaklini \\ National Aeronautics and Space Administration \\ Lewis Research Center \\ Cleveland, Ohio 44135
}

\begin{abstract}
The reliability of $100 \mathrm{MHz}$ scanning laser acoustic microscopy (SLAM) for detecting internal voids in sintered specimens of silicon nitride and silicon carbide was evaluated. The specimens contained artificially implanted voids and were surface ground. The voids ranged from 20 to $430 \mu \mathrm{m}$ in diameter and were positioned at depths ranging up to $2 \mathrm{~mm}$ below the specimen surface. Detection probability of 0.90 at a 0.95 confidence level was determined as a function of material, void diameter, and void depth. The statistical results presented for void detectability indicate some of the strengths and limitations of SLAM as a nondestructive evaluation technique for structural ceramics.
\end{abstract}

\section{INTRODUCTION}

Silicon nitride $\left(\mathrm{Si}_{3} \mathrm{~N}_{4}\right)$ and silicon carbide ( $\mathrm{SiC}$ ) structural ceramics are candidate materials for hot-section components in conventional and advanced heat engines (refs. 1 to 6 ). These materials have several advantages over presentiy-used metals including the ability to withstand higher operating temperatures (leading to increased fuel efficiency), greater resistance to corrosion and erosion, and an abundant, inexpensive, and nonstrategic supply of raw materials from which to form them. State-of-the-art structural ceramics exhibit wide variability in strength and low fracture toughness due to their brittle nature. Failure is generally attributed to flaws such as voids, microcracks, and impurity inclusions (refs. 7 to 11). Flaws as small as $10 \mu \mathrm{m}$ in structural ceramic components have been determined to be potentially failurecausing (refs. 8, 12, and 13).

The application of nondestructive evaluation (NDE) to fracture control of brittle structural components is discussed in references 7 and 12 to 15 . Sensitive, reliable NDE techniques are needed to detect potentially failurecausing flaws in structural ceramic components before these components enter service (refs. 12 to 16). Scanning Laser Acoustic Microscopy (SLAM) is among the NDE techniques that appear suitable for structural ceramics because of its ability to image surface and internal microflaws in these materials in real time (refs. 10, 15, and 17 to 22). A recent study showed SLAM to be reliable for detecting small, artificially-produced surface craters (simulating naturally-occurring surface flaws) in smoothly-ground structural ceramic specimens (ref. 19). To date, however, the reliability of SLAM for detecting internal flaws in similar specimens has not been evaluated.

This report describes a study that was conducted to evaluate the reliability of SLAM for detecting internal voids in sintered silicon nitride and sintered silicon carbide. Surface ground specimens containing statistically significant populations of artificially-seeded voids were inspected with 
SLAM. The voids covered a wide range of sizes and depths. The effects of void diameter, void depth, material microstructure, and specimen surface condition on void detectability were determined.

\section{TEST SPECIMENS}

Twelve sintered $\mathrm{Si}_{3} \mathrm{~N}_{4}$ (SSN) specimens containing a total of 189 seeded internal voids and 10 sintered SiC (SSC) specimens containing a total of 168 seeded internal voids were inspected with SLAM. The processing steps used to fabricate the test specimens are shown in figure 1 and described in detail in reference 16. Briefly, plastic microspheres of various sizes were embedded in green specimens and later burned out to create voids within sintered specimens. During formation of a specimen, a powder layer with the microspheres exposed to the surface was photographed so that approximate positions of the resulting voids would be known for SLAM inspections.

Table I describes the sintered specimens in detail. The specimens, similar in shape to modulus-of-rupture (MOR) test bars, were approximately $30 \mathrm{~mm}$ long and $6 \mathrm{~mm}$ wide and varied in thickness from 2 to $4 \mathrm{~mm}$ for SSN and 1 to $4 \mathrm{~mm}$ for SSC. Although the magnitude of the surface roughness varied, the roughness was relatively ordered (unidirectional) due to surface grinding. The SSN specimens contained less porosity than the SSC specimens and had an average grain size approximately an order of magnitude smaller than that for SSC specimens. The positions of seeded voids are illustrated in figure 2 which shows top (thru-thickness) and side view (thru-width) microfocus radiographs of a region in a typical SSN test bar.

Representative seeded internal voids in SSN and SSC specimens are shown exposed to the surface in the micrographs of figure 3 . The seeded voids were similar in morphology to naturally-occurring voids in fractured MOR bars of the same material (ref. 16). The voids ranged from 20 to $430 \mu \mathrm{m}$ in diameter in SSN and from 50 to $340 \mu \mathrm{m}$ in diameter in SSC and were positioned at depths ranging up to $2 \mathrm{~mm}$ below the specimen surface in both materials.

\section{PROCEDURES}

The procedures used to determine the reliability of SLAM for detecting internal voids in SSN and SSC specimens consisted of three major steps: inspection, void characterization, and statistical analysis.

\section{Inspection}

The specimens were alternately ground to remove material from the surface and inspected with SLAM so that detectability data for the same seeded void population could be gathered for various depths. The SLAM apparatus used for inspection of the ceramic test bars is shown in figure 4 and described in detail in references 17, 19, and 20. Briefly, continuous $100 \mathrm{MHz}$ ultrasonic waves traveling thru the specimen produce microdistortions on the specimen surface opposite the incident sound source. The distortion pattern, determined by the microstructural, bulk, and surface features of the material, is transmitted via water coupling to the reflective coating of a plastic coversip placed on the specimen. A rastering laser beam, modulated by the distortion 
pattern, is reflected to a photodetector and converted to an electronic signal. In this matter, an "acoustic" image of the specimen, including surface and internal flaws such as voids, inclusions, and cracks, is obtained and displayed on a video monitor in real-time. Only specimens having nearly flat and parallel surfaces can be inspected using the SLAM configuration shown in figure $4(b)$. The surface of the specimen nearest the laser is herein defined as the "laserscanned" surface for discussion purposes.

The surface grinding procedure was performed by hand using a 15, 30, or $45 \mu \mathrm{m}$ diamond disc attached to a rotating metallographic polishing wheel. Material was ground from the laser-scanned surface in increments of approximately 5 to $50 \mu \mathrm{m}$ to reduce the relative depth of the seeded voids and ultimately expose them. The thickness of the specimen before and after each surface grinding was measured using a digital micrometer accurate to 1 um. Microfocus radiography after several grindings confirmed the new relative positions of the seeded voids.

Detectability data (detected versus not detected) for the seeded voids was gathered during each SLAM inspection. Detection of a seeded internal void was based on distinguishing the diffraction pattern of the void (ref. 20) from background noise (ref. 12) caused by naturally-occurring flaws or surface roughness. The thickness of the specimen at which each void was initially detected was noted. Once detected at a given depth, a void was assumed to be detected at all lesser depths and (except for voids in selected specimens) did not undergo further inspections.

\section{Void Characterization}

After being exposed to the surface, the dimensions of each void were measured and the depth at which the void was initially detected with SLAM was determined (see fig. 5). The voids were ellipsoidal with the dimension of the void in the $z$-direction always shorter than the dimension in the $x$-direction (ref. 16). The depth at which a void was initially detected was calculated by subtracting the specimen thickness at which the void was just exposed to the surface from the thickness at the inspection during which the void was initially detected. The estimated error in the void dimension and depth measurements was approximately 10 percent.

\section{Statistical Analysis}

Since a seeded void was either detected or not detected (only two possible outcomes) during SLAM inspections, detection reliability was determined using binomial distribution statistics (ref. 19, 23, and 24). The equation for the cumulative binomial distribution yields detection reliability in the form of probability of detection (POD) at a pre-determined confidence level. POD calculated at a 0.95 confidence level is considered an appropriate measure of the reliability of an NDE inspection technique (ref. 19, 23, and 24) and was used in this study to describe detection reliability with SLAM.

Detectability data was grouped according to void depth below the laserscanned surface for each material. Depth ranges were (in micrometers): 0 to 25,25 to 50,50 to 100,100 to 150,150 to 200,200 to 300,300 to 400,400 to 500,500 to 600,600 to 700,700 to 800,800 to 900,900 to 1000,1000 to 
1200,1200 to 1400,1400 to 1600,1600 to 1800 , and 1800 to 2000 . As previously noted, a void was assumed detected at all lesser depths than that at which it was initially detected. The data at each depth range was grouped into intervals according to void diameter so that every interval contained at least one void and a void did not appear in more than one interval. The smallest interval used was $10 \mu \mathrm{m}$. The larger void dimension (in the $x$-direction) was taken to be the void diameter (see fig. 5). The optimized-probability method (ref. 19, 23, and 24) was used to further arrange the void diameter data because the number of voids in many intervals was insufficient for a valid statistical sample. This method increases the size of the sample used to calculate probability by including inspection data from intervals containing smaller voids. The use of the optimized probability method is justified by assuming that POD increases with increasing void diameter (ref. 23).

POD was calculated over the diameter intervals and curves were plotted at each depth range using a modified version of the fortran computer program listed in reference 19. The values of POD were plotted (conservatively) at the largest void diameter contained in the interval over which POD was calculated. Since 0.90 POD calculated at a 0.95 confidence level is statistically significant (ref. 25), the void diameters at which at least 0.90 POD (at a 0.95 confidence leve1) was achieved were determined from the curves at each depth range for SSN and SSC.

Possible biases resulting from the use of a limited statistical sample of voids, the use of single versus multiple inspections, and prior knowledge of approximate seeded void locations were offset by basing POD calculations on the largest void dimension, calculating POD at a 0.95 confidence level, and plotting a POD value at the largest void diameter in the interval over which POD was calculated.

\section{RESULTS}

Detectability data for the seeded voids and corresponding POD curves at each depth range for SSN and SSC specimens are given in appendices $A$ and $B$, respectively. Curves are not presented for the 700 to $2000 \mu \mathrm{m}$ depth ranges for SSC because POD was zero at depths greater than $700 \mu \mathrm{m}$ in the SSC specimens. Figure 6 shows a sample set of detectability data and corresponding POD curve for seeded voids 300 to $400 \mu \mathrm{m}$ deep in SSN. Voids $190 \mu \mathrm{m}$ in diameter or larger were detected with at least 0.90 probability at this depth range in SSN.

Figure 7 shows a plot of 0.90 POD as a function of material, void diameter, and void depth. The range of depths and diameters for which 0.90 or higher POD was achieved is indicated by the outlined regions. for SSN and SSC. As examples, voids approximately 50, 200, and $400 \mu \mathrm{m}$ in diameter in SSN were detected with at least 0.90 probability if within 100,800 , and $1400 \mu \mathrm{m}$ of the laser-scanned surface, respectively. Voids approximately 75, 200, and $300 \mu \mathrm{m}$ in diameter in SSC were detected with at least 0.90 probability if within 25 , 100 , and $150 \mu \mathrm{m}$ of the laser-scanned surface, respectively. The smallest voids for which 0.90 POD was achieved were $30 \mu \mathrm{m}$ in diameter in SSN and $60 \mu \mathrm{m}$ in diameter in SSC. It is worth noting that this result was 1imited by the sma11est seeded voids upon which statistical data was gathered ( $20 \mu \mathrm{m}$ in diameter in SSN and $50 \mu \mathrm{m}$ in diameter in SSC) and the conservative plotting procedure used for the POD curves. It is felt that 0.90 POD would have been achieved for voids on the order of $10 \mu \mathrm{m}$ in diameter if within approximately $25 \mu \mathrm{m}$ of the 
laser-scanned surface in both materials. Figure 7 shows that for either SSN or SSC, 0.90 POD was achieved over greater depths for larger voids than for smaller voids and that for equally-sized voids, 0.90 P0D was achieved over considerably greater depths in SSN than in SSC.

Points outside an outlined region indicate diameters and depths of voids that may have been detected but with less than 0.90 probability. At depths of 1400 to $2000 \mu \mathrm{m}$ in SSN and 200 to $2000 \mu \mathrm{m}$ in SSC, no voids in the size range investigated were detected with 0.90 probability (see appendices $A$ and $B$ ). This occurred either because void detectability was low, as was the case for SSC, or a sufficient statistical sample of voids was unavailable at the larger void diameters, as was the case for SSN.

\section{DISCUSSION}

The reliability of SLAM for detecting internal voids in structural ceramics with as-ground surfaces is a function of material, void size, and void depth. The effect of these variables on void detectability with SLAM is illustrated in the acoustic micrographs of figures 8 to 10 . These micrographs show selected voids (those in figs. 3(a) to (c), respectively) acoustically imaged at various depths before being exposed.

The initial SLAM detection of each void was accomplished by noting the appearance of a diffuse, ring-like diffraction pattern (see figs. $8(a), 9(a)$, and $10(a))$. As the relative depth of each void was reduced by grinding away material from the laser-scanned surface, the void's diffraction pattern became more pronounced making the void easier to detect. As shown in figures $8(b)$ to (d), 9 (b) to (d), and 10 (b) to (c), the first (innermost) diffraction ring became less diffuse and/or additional (concentric) diffraction rings began to appear as the relative depth was reduced. Hence, once detected at a given depth, a void would be detected at lesser depths.

As expected, a larger void was more easily detected than was a smaller void at a given depth in either SSN or SSC. This can be seen by comparing the acoustic images of a $30 \mu \mathrm{m}$ void (fig. 8(a)) and a $400 \mu \mathrm{m}$ void (fig. 9(d)) approximately $100 \mu \mathrm{m}$ below the laser-scanned surface in SSN. Similarly, larger voids were initially detected at greater depths than were smaller voids. As shown in figures 8 and 9 , respectively, a $30 \mu \mathrm{m}$ void was first detected at a depth of approximately $100 \mu \mathrm{m}$ while a $400 \mu \mathrm{m}$ void was first detected at a depth of approximately $1700 \mu \mathrm{m}$ in SSN. This explains why 0.90 POD was achieved over greater depths for larger voids than for smaller voids in either SSN or SSC ( see fig. 7).

At any given depth, voids were generally easier to detect in SSN than in SSC. Moreover, a much sharper decrease in void detectability with increasing depth was observed for SSC as compared with SSN. The acoustic images of SSC were typically noisier than those of SSN making the acoustic diffraction patterns of voids more difficult to distinguish in SSC than in SSN. These findings indicated that SSC contained more acoustic scattering sites that were undoubtedly due to the markedly coarser grain structure and greater porosity of SSC (ref. 26 and 27). The difference in void detectability between the two materials is illustrated by comparing figures 8 and 10 . At similar depths, the diffraction pattern of a $30 \mu \mathrm{m}$ void in SSN (see fig. 8) was much easier to discern than that of a $100 \mu \mathrm{m}$ void in SSC (see fig. 10). These factors explain 
why 0.90 POD was achieved over much greater depths in SSN than in SSC for similarly-sized voids (see fig. 7).

Figure 11 illustrates the effect of surface condition on void detectability in structural ceramics with SLAM. Void detectability was shown in reference 19 to critically depend on the condition of the laser-scanned surface. In that study, significant background noise was present in the acoustic images of as-fired specimens. Seeded surface voids were masked by the noise making them difficult if not impossible to detect. Background noise was substantially reduced after polishing only the laser-scanned surface. Consequently, the seeded surface voids were readily detected.

In this study, background noise attributable to surface roughness effects was negligible because the laser-scanned surface was in the as-ground condition. (The opposite surface of the specimen was left in the as-fired condition.) Only weak striations produced by grinding marks were apparent in acoustic images (see fig. $9(a)$ ), and the diffraction patterns of internal voids dominated.

\section{CONCLUSION}

The reliability of $100 \mathrm{MHz}$ scanning laser acoustic microscopy (SLAM) for detecting internal voids in surface ground specimens of sintered silicon nitride (SSN) and sintered silicon carbide (SSC) was evaluated over a wide range of void sizes and depths. Detection probability of 0.90 at a 0.95 confidence level was determined as a function of material, void diameter, and void depth. In either SSN or SSC, 0.90 detection probability was achieved over greater depths for larger voids than for smaller voids. Voids as small as $30 \mu \mathrm{m}$ in diameter in SSN and $60 \mu \mathrm{m}$ in diameter in SSC were detected with 0.90 probability but only if relatively close to the specimen surface. For similarly-sized voids, 0.90 detection probability was achieved over considerably greater depths in SSN than in SSC. The statistical results presented herein for void detectability indicate some of the strengths and limitations of SLAM as a nondestructive evaluation technique for structural ceramics. 


\section{APPENDIX A}

SINTERED SILICON NITRIDE DATA

Detectability data and corresponding probability of detection curves at each depth range for the seeded internal voids in sintered silicon nitride appear in figures $12(a)$ to $12(r)$. 


\section{APPENDIX B}

SINTERED SILICON CARBIDE DATA

Detectability data and corresponding probability of detection curves at each depth range for the seeded internal voids in sintered silicon carbide appear in figures $13(a)$ to $(j)$. 


\section{REFERENCES}

1. A.P.S. Teotia, and L.R. Johnson, "Structural Ceramics in Transportation: Fuel Implications and Economic Aspects," CONF-850115-4, Dept. of Energy, 1985.

2. R.B. Shulz, "Overview of U.S. Department of Energy Ceramic Gas Turbine Program," pp. 21-28 in Ceramics for High-Performance Applications III: Rellability, Edited by E.M. Lenoe, R.N. Katz and J.J. Burke, Plenum Press, New York, 1983.

3. R.N. Katz, "Ceramics for Vehicular Engines: State-of-the-Art?," pp. 449-467 in Energy and Ceramics, Edited by P. Vincenzini, Elsevier, Amsterdam, 1980.

4. J.E. Harper, "ARPA/NAVAIR Ceramics Gas Turbine Engine Demonstration Program," pp. 123-149 in Ceramics for High-Performance Applications III:

Reliability, Edited by E.M. Lenoe, R.N. Katz and J.J. Burke, Plenum Press, New York, 1983.

5. E.M. Lenoe, "Recent Accomplishments and Research Needs in Structural Ceramics," pp. 3-18 in Ceramics for High-Performance Applications III: Reliability, Edited by E.M. Lenoe, R.N. Katz and J.J Burke, Plenum Press, New York, 1983.

6. S. Bortz, "Reliability of Ceramics for Heat Engine Applications," pp. 445-473 in Ceramics for High-Performance Applications III: Reliability, Edited by E.M. Lenoe, R.N. Katz and J.J. Burke, Plenum Press, New York, 1983.

7. A.G. Evans, "Aspects of the Reliability of Ceramics," pp. 63-80 in Defect Properties and Processing of High-Technology Nonmetallic Materials, Edited by J.H. Crawford Jr., Y. Chen and W.A. Sibley, North Holland, New York,, 1984.

8. A.G. Evans, G.S. Kino, B.T. Khuri-Yakub, and B.R. Jittman, "Failure Prediction in Structural Ceramics," Mater. Eval., 35, [4] 85-96 (1977).

9. A.G. Evans, "Structural Reliability: A Processing-Dependent Phenomenon," J. Am. Ceram. Soc., 65 [3] 127-137 (1982).

10. P.W. Heitman, and P.K. Khandelwal, "Development and Characterization of Ceramic Turbine Components," pp. 645-664 in Ceramics for High-Performance Applications III: Reliability, Edited by E.M. Lenoe, R.N. Katz and J.J. Burke, Plenum Press, New York, 1983.

11. H.K. Bowen, "Basic Research Needs on High Temperature Ceramics for Energy Applications." Mater. Sci. Eng., 44 [1] 1-56 (1980).

12. R.W. Rice, J.J. Mecholsky, S.W. Freiman, and S.M. Morey, "Failure Causing Defects in Ceramics: What NDE Should Find," NRL-MR-4075, Naval Research Lab, 1979. 
13. R.W. Rice, and D. Lewis III, "Limitations and Challenges in Applying Fracture Mechanics to Ceramics," pp. 659-676 in Fracture Mechanics of Ceramics, Vol. 5, Surface Flaws, Statistics, and Microcracking, Edited by R.C. Bradt, A.G. Evans, D.P.H. Hasselman and F.F. Lange, Plenum Press, New York, 1983.

14. R.D. Streit, "Requirements of Quantitative NDE in Developing Fracture Control Plans," UCRL-90716, Lawrence Livermore National Lab, 1984.

15. S.J. KTima, "NDE for Heat Engine Ceramics," NASA TM-86949, 1984.

16. G.Y. Baaklini, and D.J. Roth, "Probability of Detection of Internal Voids in Structural Ceramics Using Microfocus Radiography," NASA TM-87164, 1985.

17. L.W. Kessler, and D.E. Yuhas, "Acoustic Microscopy - A Tutorial Review," pp. 275-313 in Acoustical Imaging, Vol. 9, Visualization and Characterization, Edited by K.Y. Wang, Plenum, New York, 1980.

18. D.S. Kupperman, L. Pahis, D. Yuhas, and T.E. McGraw, "Acoustic Microscopy Techniques for Structural Ceramics," Am. Ceram. Soc. Bull., 59 [8] 814-816, 839-841 (1980).

19. D.J. Roth, S.J. Klima, J.D. Kiser and G.Y. Baaklini, "Reliability of Void Detection in Structural Ceramics Using Scanning Laser Acoustic Microscopy," NASA TM-87035, 1985.

20. E.R. Generazio, and D.J. Roth, "Quantitative Flaw Characterization with Scanning Laser Acoustic Microscopy," to appear in Proceedings of Analytical Ultrasonics in Materials Research and Testing Conf. held at NASA-Lewis Research Center, Cleveland, $\mathrm{OH}$, Nov. 1984.

21. D.E. Yuhas, and L.W. Kessler, "Defect Characterization by Means of The Scanning Laser Acoustic Microscope (SLAM)," pp. 301-303 in Acoustical Imaging, Vol. 9, Visualization and Characterization, Edited by K.Y. Wang, Plenum Press, New York, 1980.

22. D.E. Yuhas, T.E. McGraw, and L.W. Kessler, "Scanning Laser Acoustic Microscope Visualization of Solid Inclusions in Silicon Nitride," pp. 683-690 in Proceedings of the DARPA/AFML Review of Progress in Quantitative Nondestructive Evaluation, Edited by D.O. Thompson and R.B. Thompson, AFWALTR-80-4078, 1980. (AD-A094826.)

23. P.F. Packman, et al., "Reliability of Flaw Detection by Nondestructive Inspection," pp. 414-424 in Metals Handbook, Vol. 11, Nondestructive Inspection and Quality Control, American Society For Metals, Metals Park, $\mathrm{OH}, 1976$.

24. B.G.W. Yee, F.H. Chang, J.J Couchman, G.H. Lemon, and P.F. Packman, "Assessment of NDE Reliability Data," NASA-CR-134991, 1976.

25. A.P. Berens, and P.W. Hovey, "Flaw Detection Reliability Criteria," AFWAL-TR-84-4022-Vol-I, Air Force Wright Aeronautical Lab, 1984, (AD-A142001). 
26. C.M. Sayers, and Smith, R.L., "The Propagation of Ultrasound in PorousMedia," Ultrasonics, 20 [5] 201-205 (1982).

27. E.P. Papadakis, "Some Practical Aspects of Research with Ultrasonic Waves," Int. J. Nondestr. Test., I [4] 383-399 (1970). 


\section{ORIGINAL PAGE IS OF POOR QUALITY}

TABLE 1. CHARACTERIZATION OF SPECIMENS

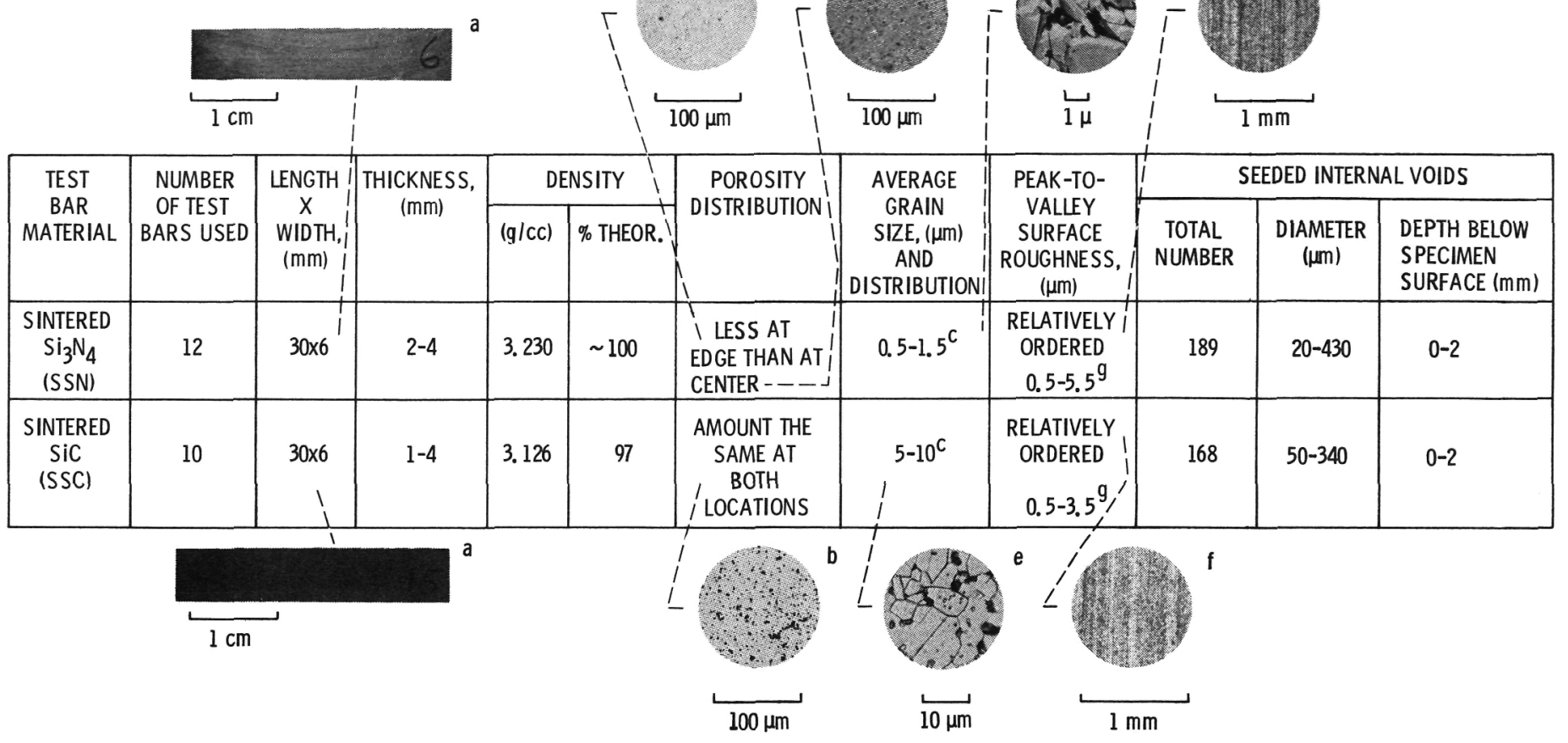

aOPTICAL PHOTOGRAPH OF DIAMOND-GROUND SPECIMEN

DOPTICAL MICROGRAPH OF POLISHED SPECIMEN (BLACK SPOTS INDICATE POROSITY)

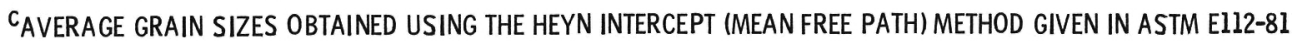

${ }^{d}$ TRANSMISSION ELECTRON MICROGRAPH OF REPLICA OF POLISHED AND ETCHED SPECIMEN

${ }^{\circledR}$ OPTICAL MICROGRAPH OF POLISHED AND ETCHED SPECIMEN

IOPTICAL MICROGRAPH OF DIAMOND-GROUND SPECIMEN

9SURFACE PROFILE (USING A 12.5 m DIAMETER DIAMOND STYLUS) OF DIAMOND-GROUND SPECIMEN PERPENDICULAR TO GRINDING MARKS 


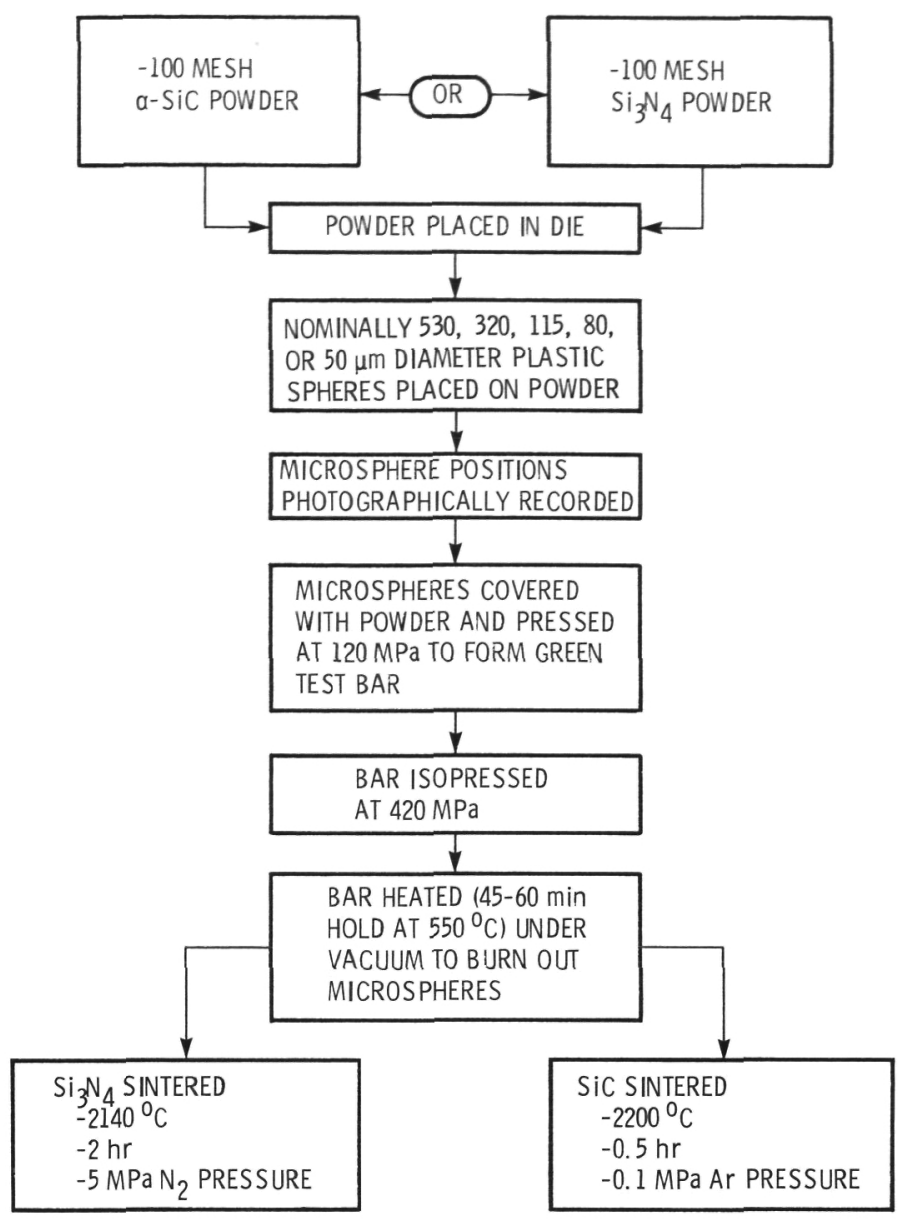

Figure 1. Fabrication of the sintered silicon nitride and sintered silicon carbide test specimens with seeded internal voids. 


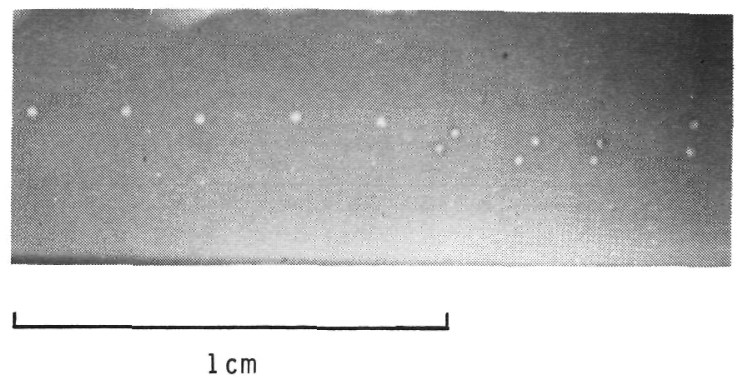

(a) Top view (thru-thickness).

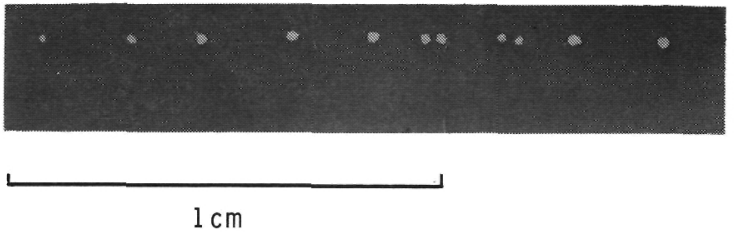

(b) Side view (thru-width).

Figure 2. - Microfocus radiographs of a region of a typical sintered silicon nitride test bar showing the location of the seeded internal voids. The white spots indicate the voids. (Initial shere size $=320 \mu \mathrm{m})$ 


\section{ORIGINAL PAGE IS \\ OF. POOR QUALITY}

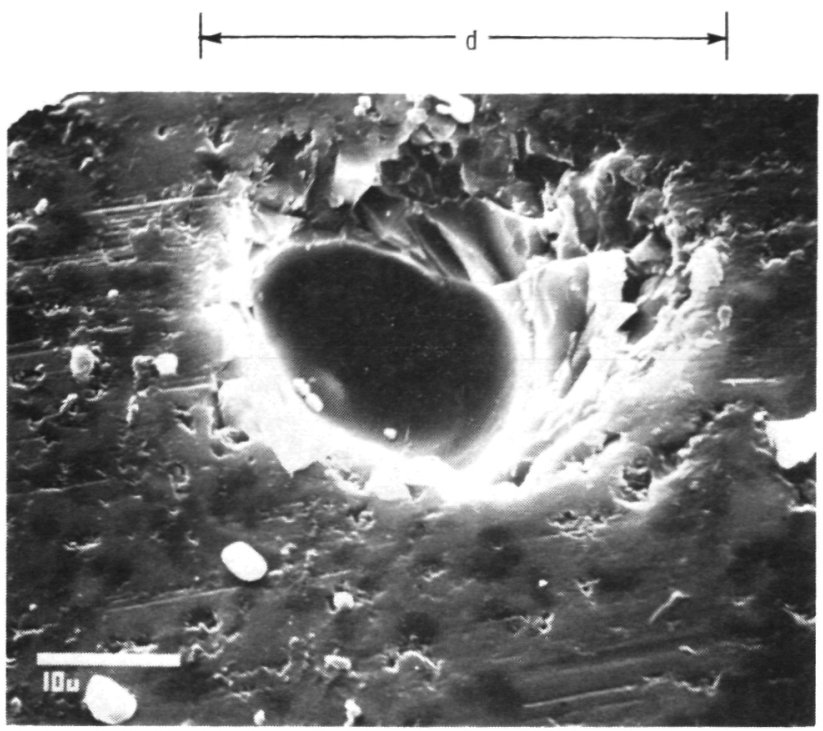

(a) Scanning electron micrograph of void approxi mately $30 \mu \mathrm{m}$ in diameter in a sintered silicon nitride specimen.

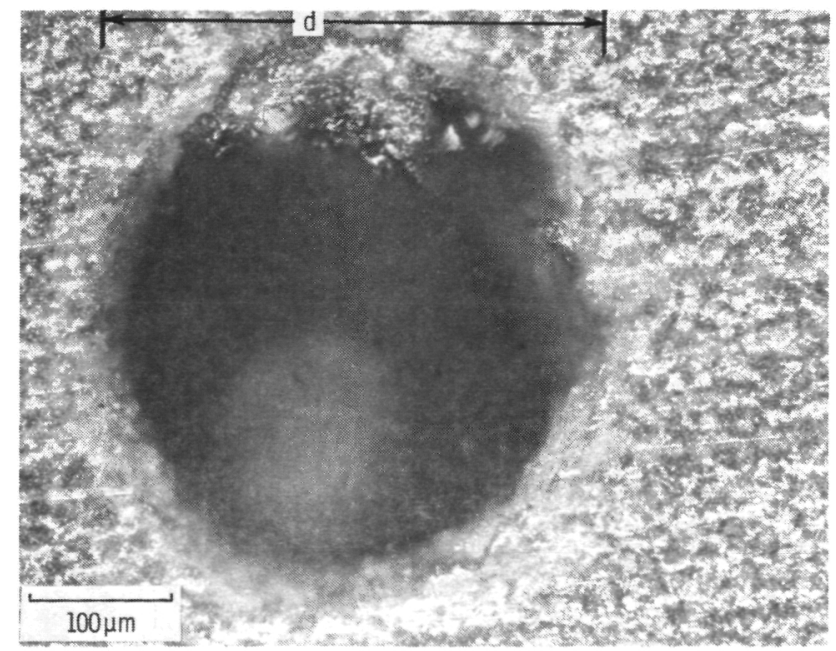

(b) Optical micrograph of void approxi mately $400 \mu \mathrm{m}$ in diameter in a sintered silicon nitride specimen.

Figure 3. - Micrographs of representative seeded internal voids exposed to the specimen surface. $(\mathrm{d}=$ diameter $)$ 
ORIGINAL PAGE IS

OF POOR QUALTY

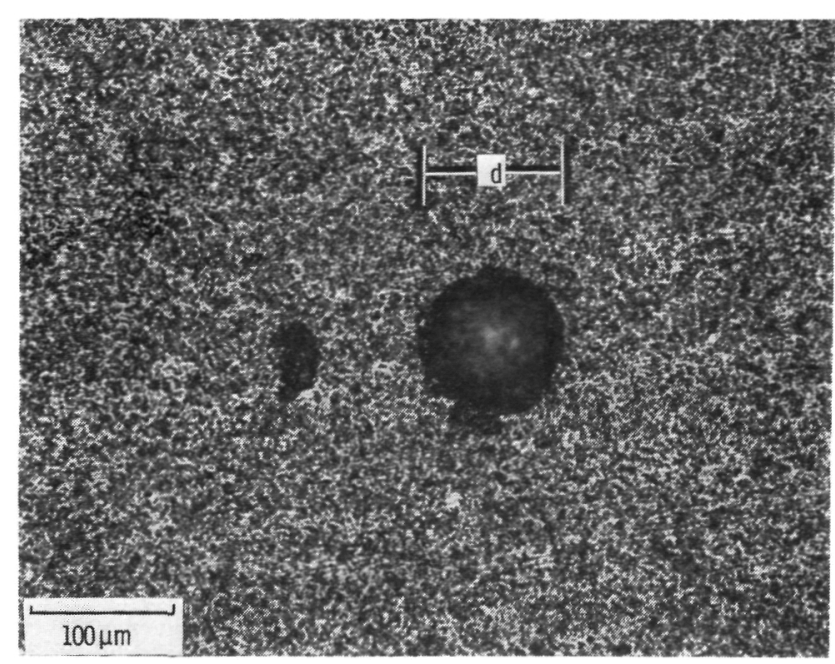

(c) Optical micrograph of void approxi mately $100 \mu \mathrm{m}$ in diameter in a sintered silicon carbide specimen.

Figure 3. - Concluded. 


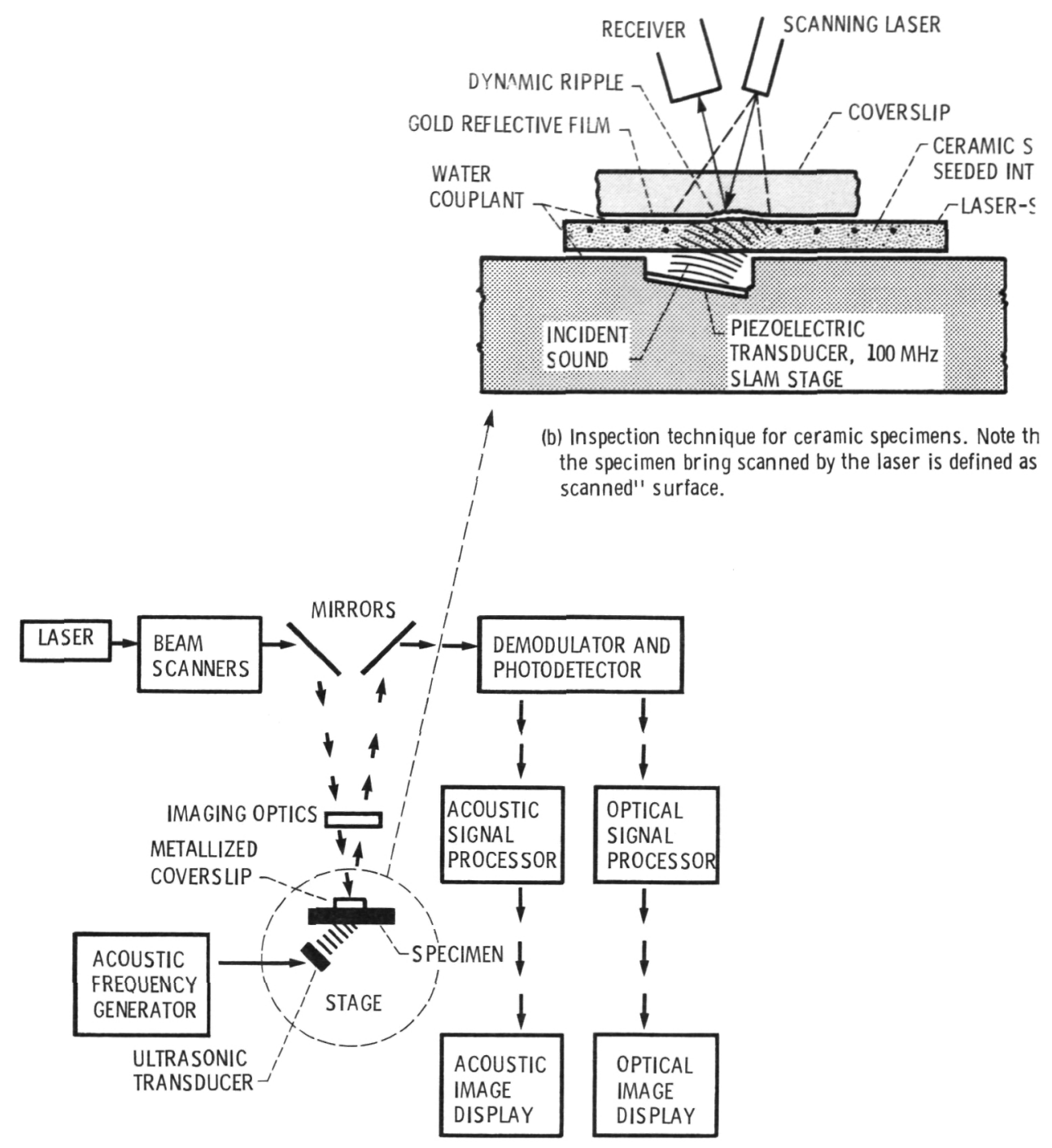

(a) Schematic diagram of scanning laser acoustic microscope.

Figure 4. - Scanning laser acoustic microscopy. 


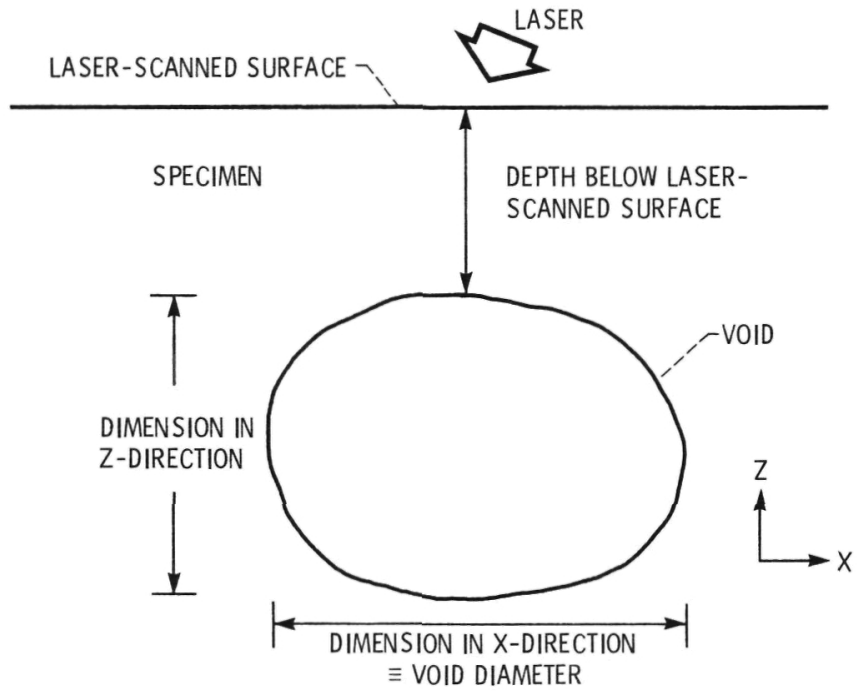

Figure 5. - Illustration showing definitions of void diameter and depth of void below the laser-scanned surface. Voids had an ellipsoidal geometry with the dimension in the Z-direction always shorter than the dimension in the X-direction. 


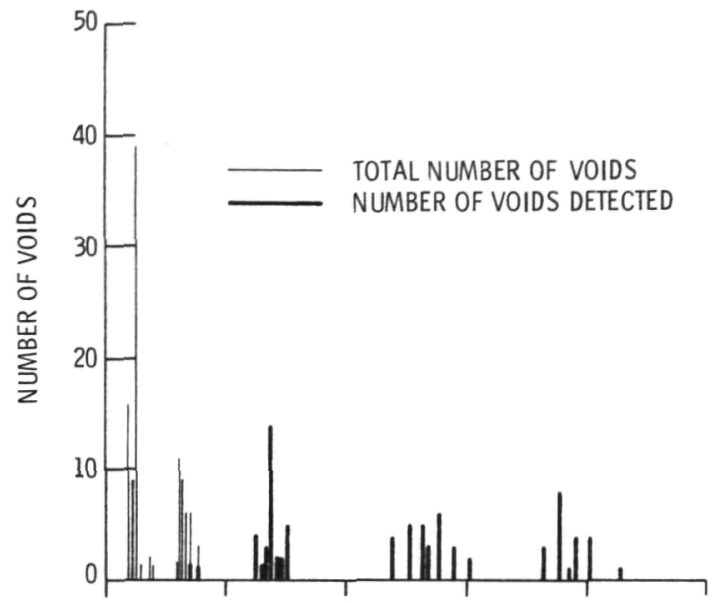

(a) Detectability data.

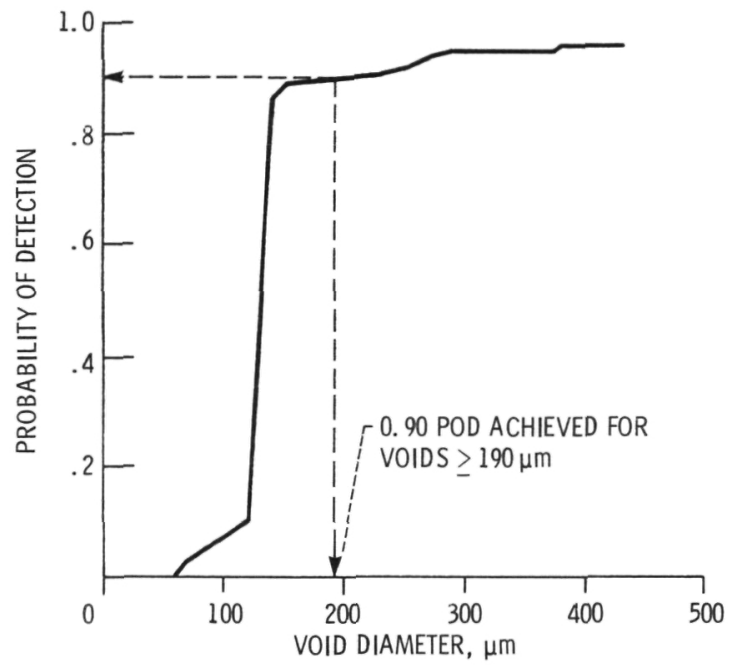

(b) Probability of detection.

Figure 6. - Detectability data and corresponding probability of detection (POD) for seeded voids $300-400 \mu \mathrm{m}$ below the laser-scanned surface in sintered silicon nitride. Probability was calculated at a 0.95 confidence level. 


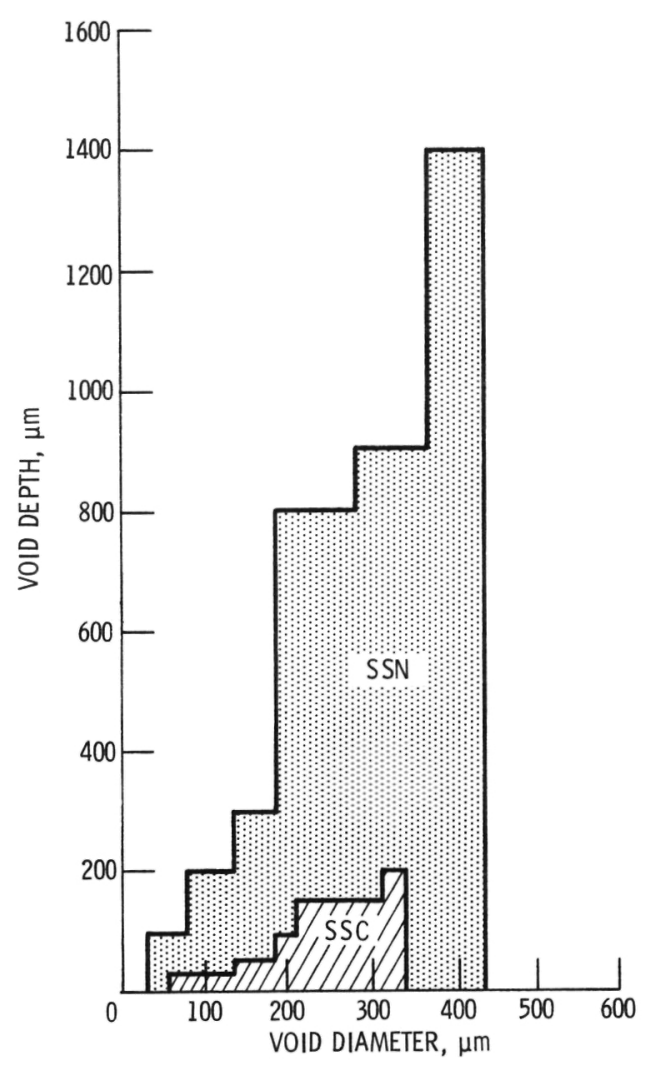

Figure 7. -0.90 Probability of detection as a function of material, void diameter, and void depth below the laser-scanned surface. SSN $\equiv$ sintered silicon nitride.

$\mathrm{SSC} \equiv$ sintered silicon carbide. 


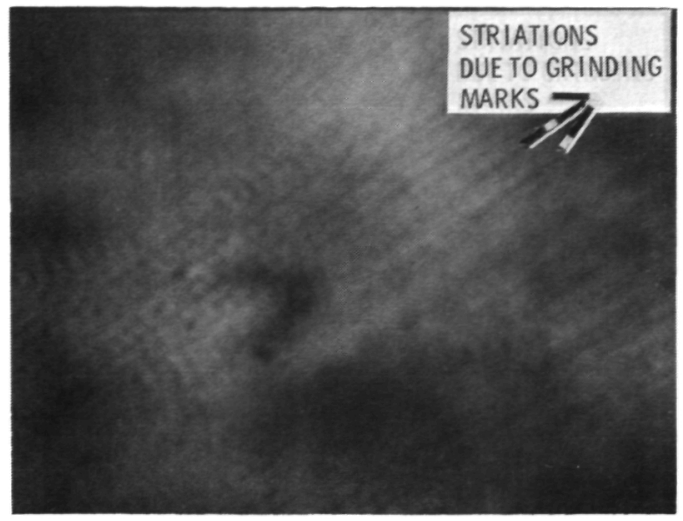

\section{ORIGINAL OF POOR PAGE IS}

(a) Void depth $\cong 100 \mu \mathrm{m}$.

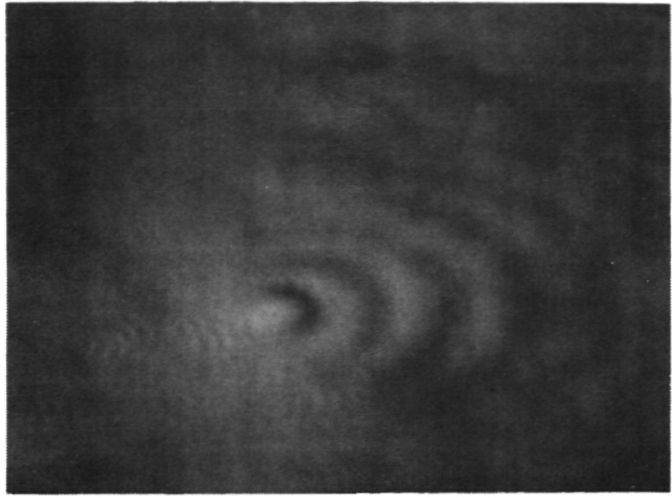

(b) Void depth $\cong 50 \mu \mathrm{m}$.

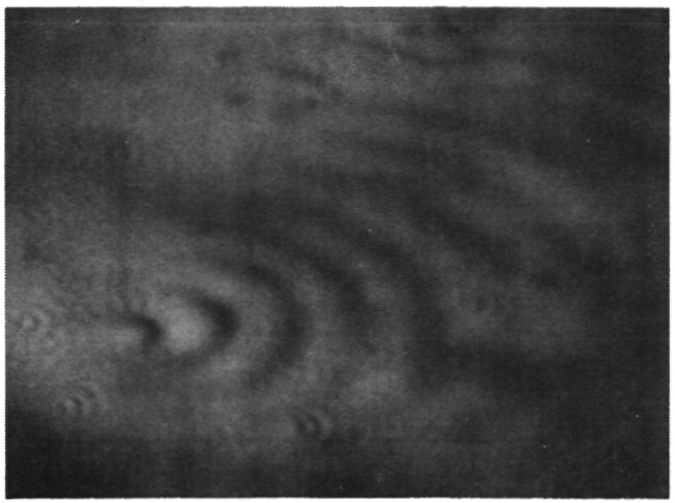

(c) Void depth $\cong 25 \mu \mathrm{m}$.

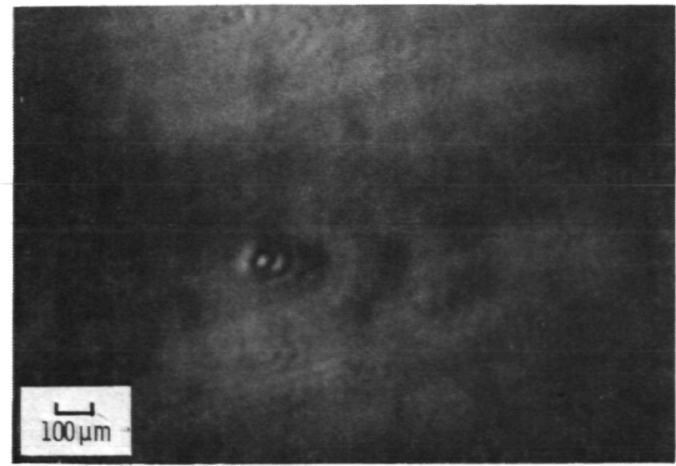

(d) Void just broken thru surface.

Figure 8. - Acoustic micrographs of a seeded internal void $30 \mu \mathrm{m}$ in diameter (shown exposed to the surface in figure 3 a) in a sintered silicon nitride specimen at various depths below the laser-scanned surface. Void was initially detected at a depth of approximately $100 \mu \mathrm{m}$. 


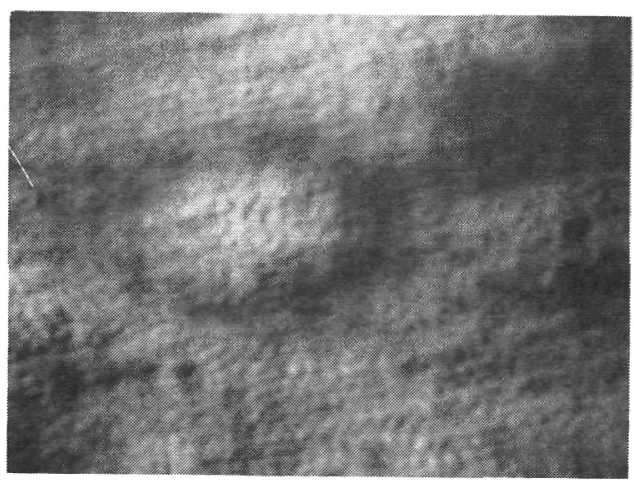

(a) Void depth $\cong 1700 \mu \mathrm{m}$.

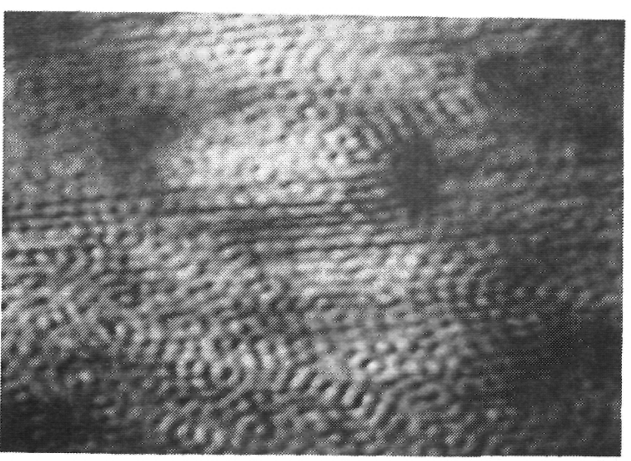

(b) Void depth $\cong 1300 \mu \mathrm{m}$.

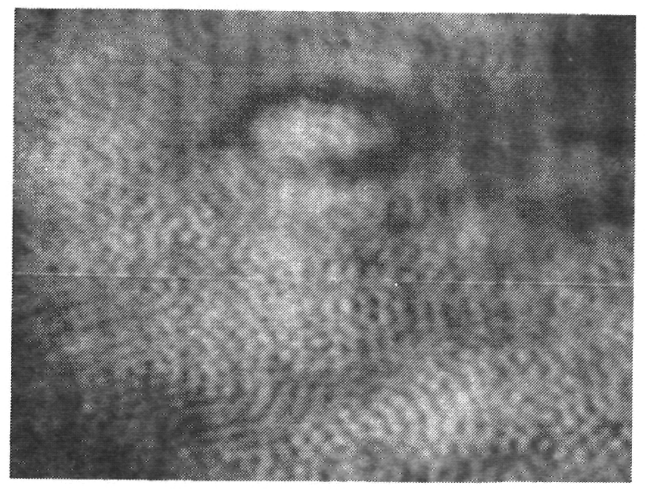

(c) Void depth $\cong 700 \mu \mathrm{m}$.

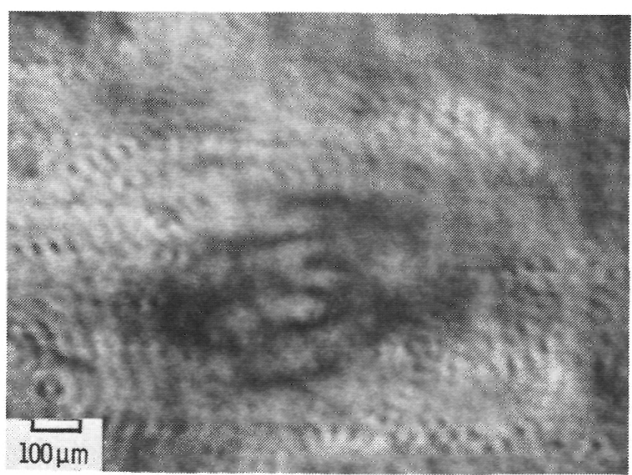

(d) Void depth $=100 \mu \mathrm{m}$.

Figure 9. - Acoustic micrographs of a seeded internal void $400 \mu \mathrm{m}$ in diameter (shown exposed to the surface in figure $3 \mathrm{~b})$ in a sintered silicon nitride specimen at various depths below the laser-scanned surface. Void was initially detected at a depth of approximately $1700 \mu \mathrm{m}$. 


\section{ORIGEINAL PAGE IS \\ OF POOP NIJALITY}

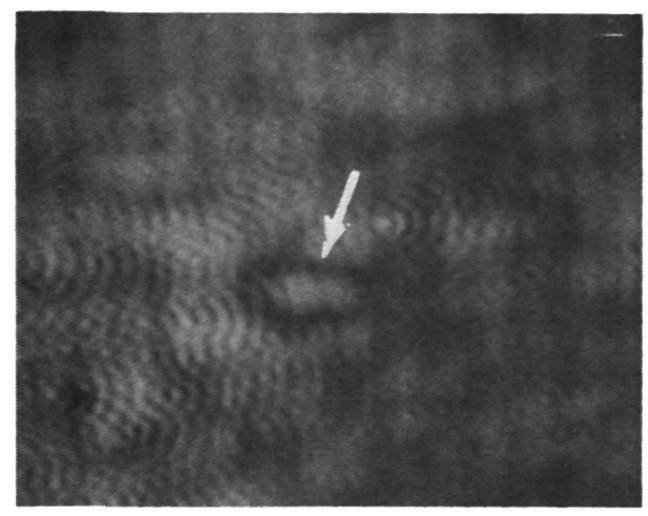

(a) Void depth $\cong 100 \mu \mathrm{m}$.

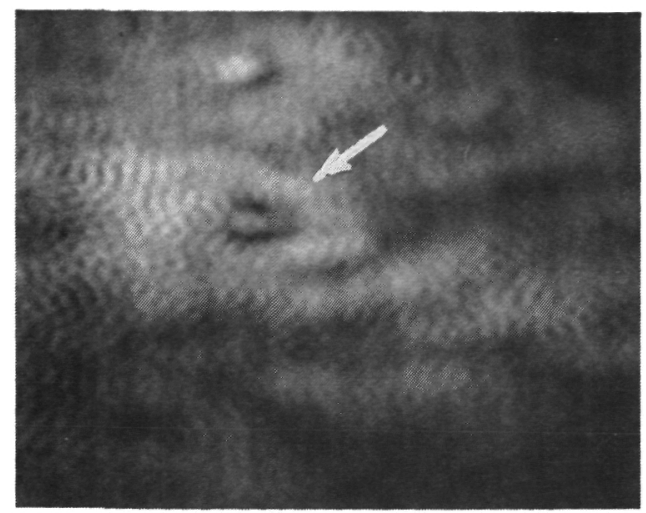

(b) Void depth $\cong 50 \mu \mathrm{m}$.

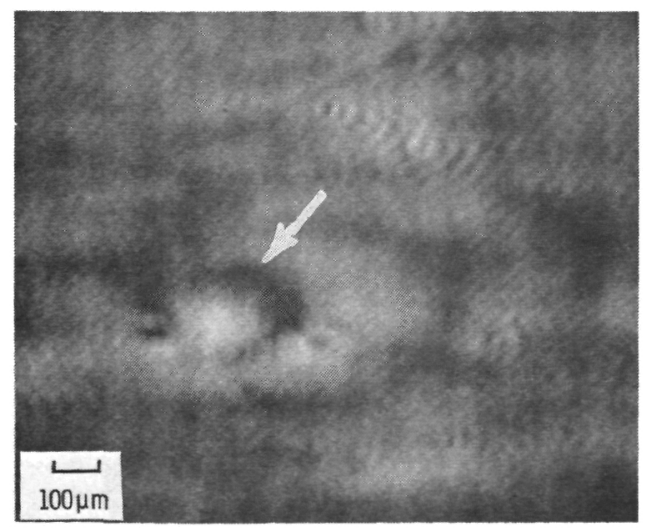

(c) Void depth $\cong 25 \mu \mathrm{m}$.

Figure 10. - Acoustic micrographs of a seeded internal void $100 \mu \mathrm{m}$ in diameter (shown exposed to the surface in figure $3 c$ ) in a sintered silicon carbide specimen at various depths below the laser-scanned surface. Void was initially detected at a depth of approximately $100 \mu \mathrm{m}$. Seeded void diffraction pattern is noted by arrow to distinguish it from the images of naturally-occuring flaws. 


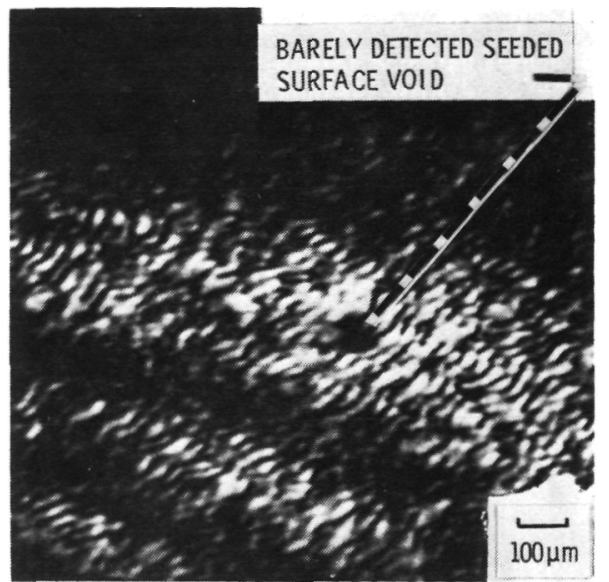

(a) Acoustic image of as-fired specimen. Noise attributed to surface roughness is substantial.

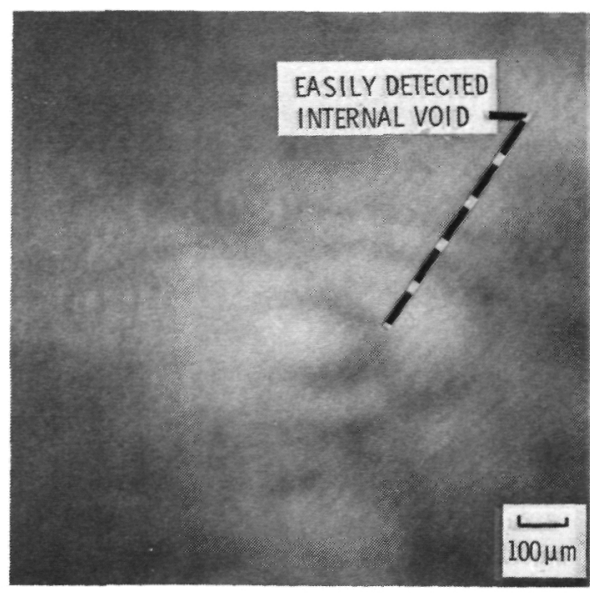

(b) Acoustic image of as-ground specimen. Noise attributed to surface roughness is negligible.

Figure 11. - Effect of surface condition on void detectability in structural ceramics with SLAM. Illustration of void detectability in as-fired specimens taken from reference 19. 

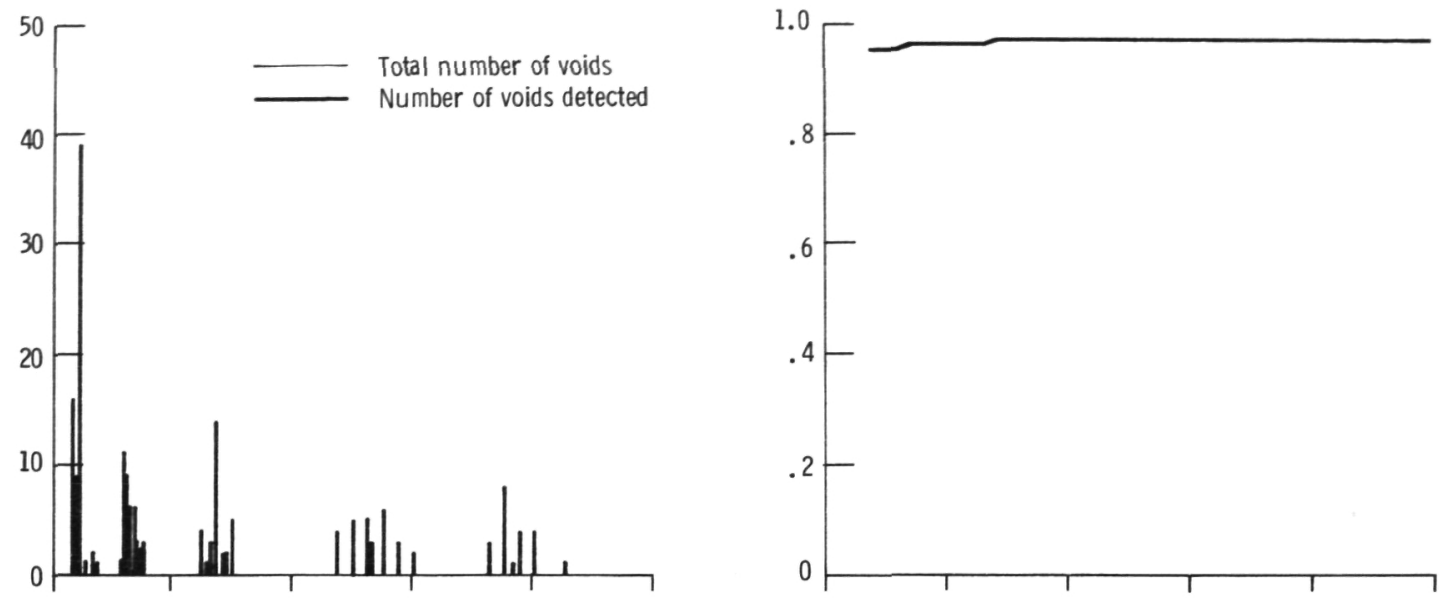

(a) Depth, 0 to $25 \mu \mathrm{m}$.
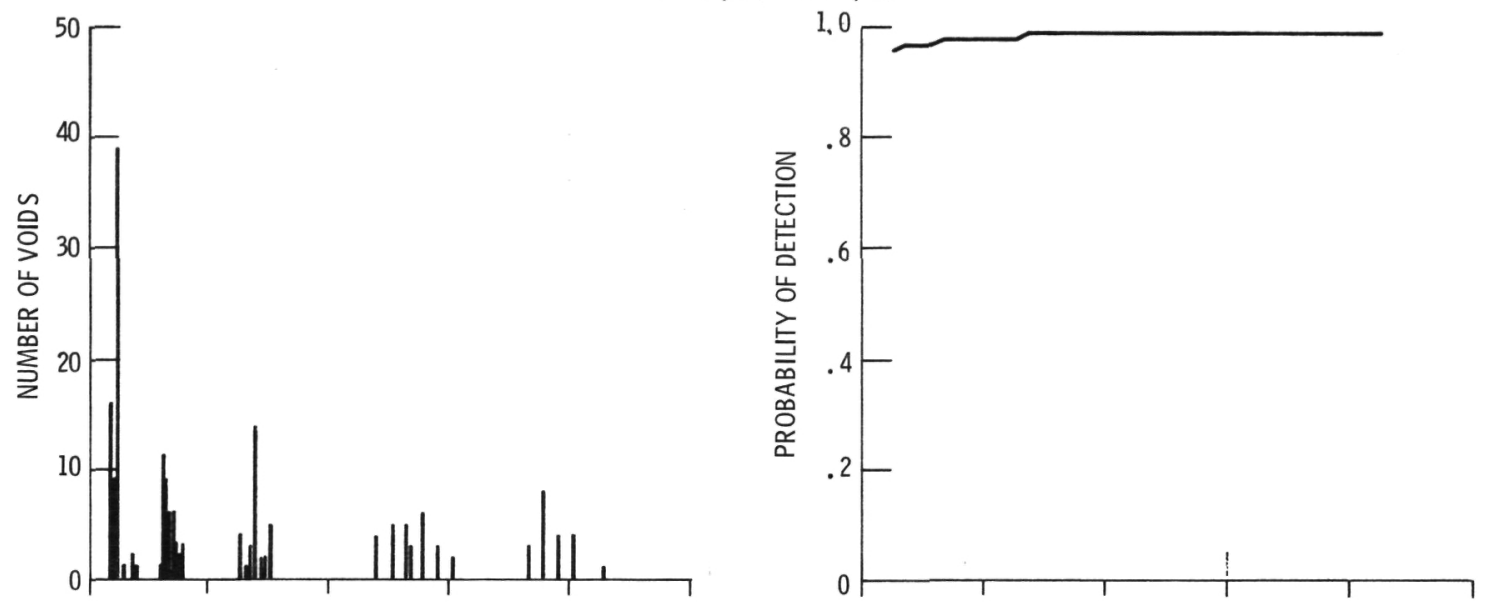

(b) Depth, 25 to $50 \mu \mathrm{m}$.
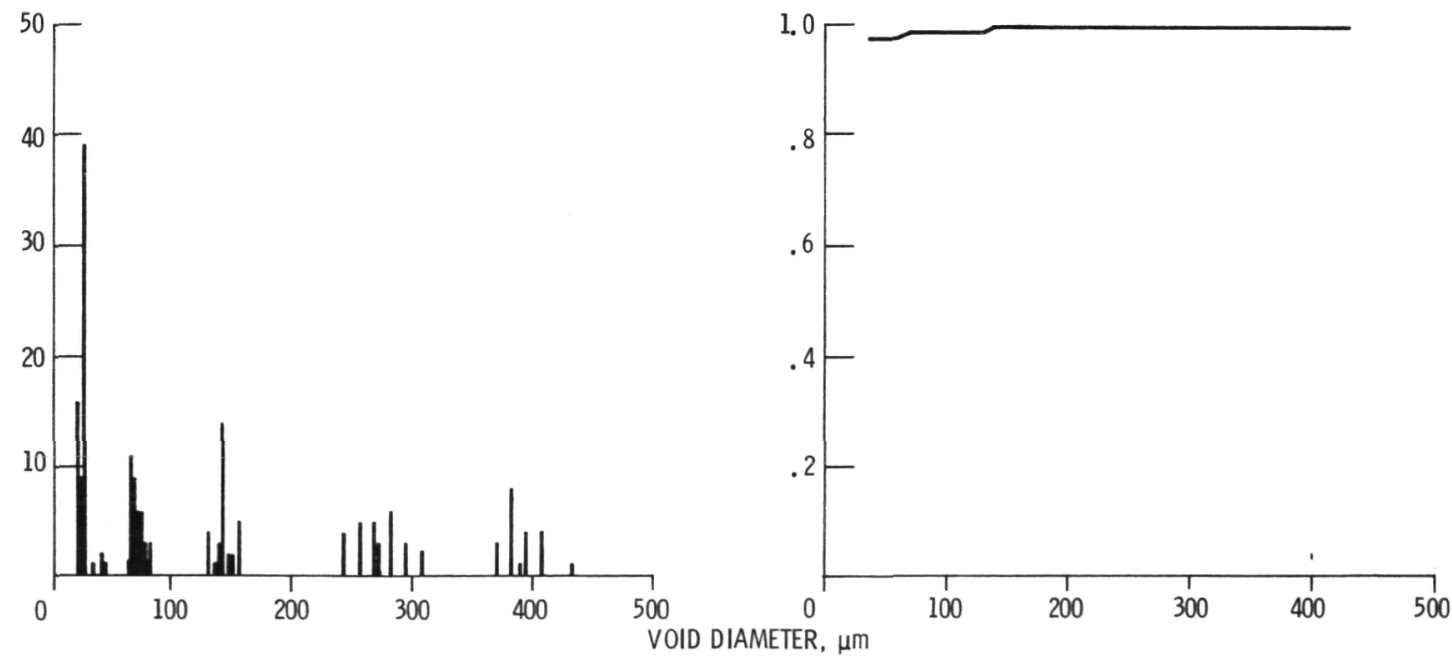

VOID DIAMETER, $\mu \mathrm{m}$

(c) Depth, 50 to $100 \mu \mathrm{m}$.

Figure 12. - Detectability data and probability of detection for seeded voids positioned below laser-scanned surface in sintered silicon nitride specimens. Probability calculated at a 0.95 confidence level. 

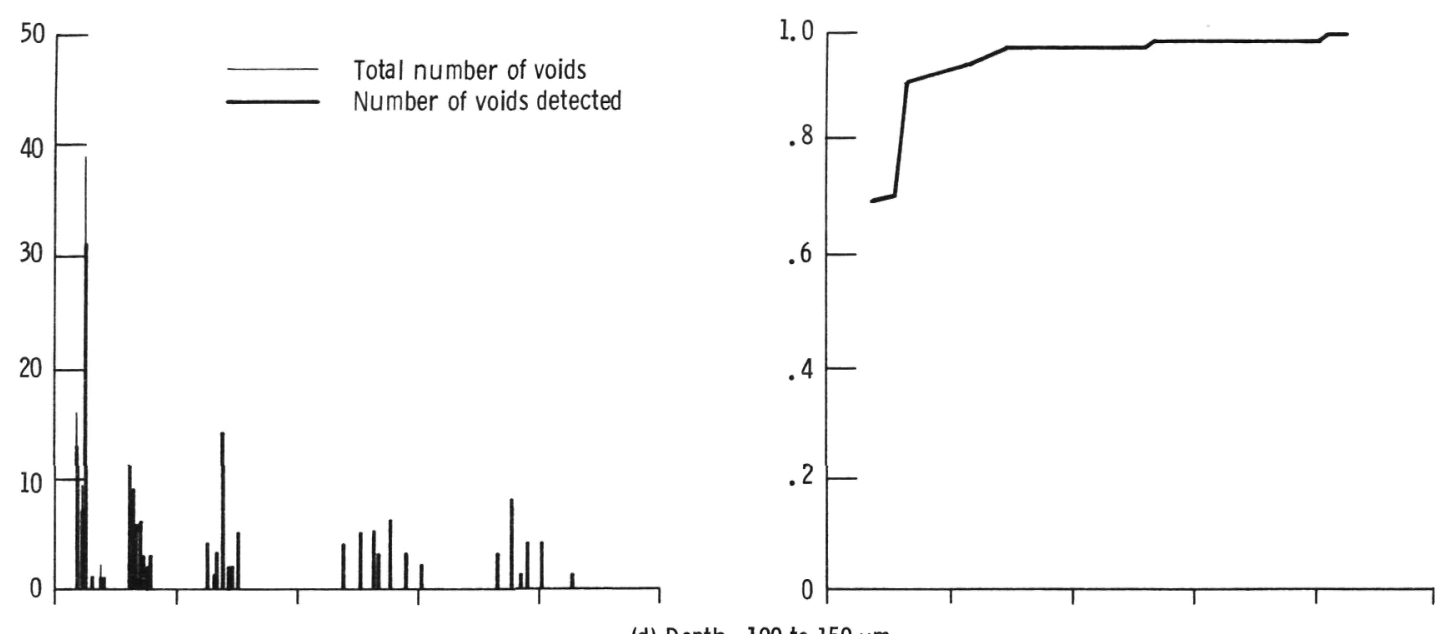

(d) Depth, 100 to $150 \mu \mathrm{m}$.
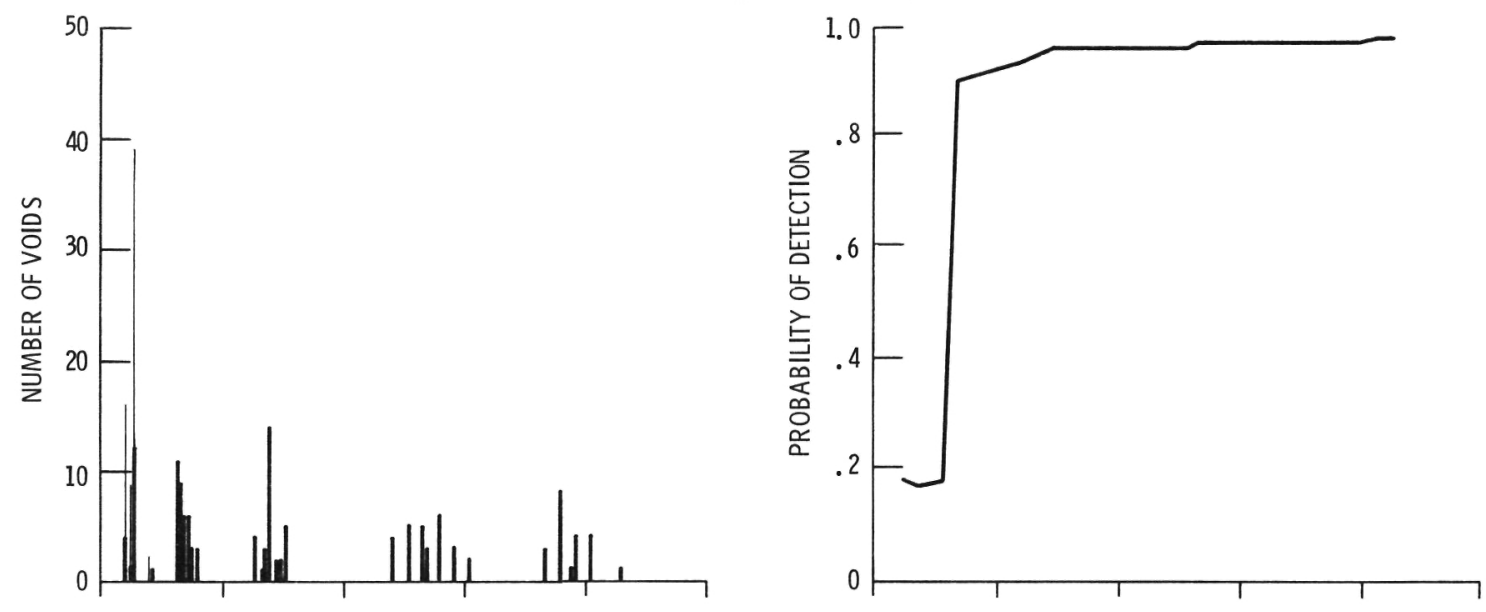

(e) Depth, 150 to $200 \mu \mathrm{m}$.
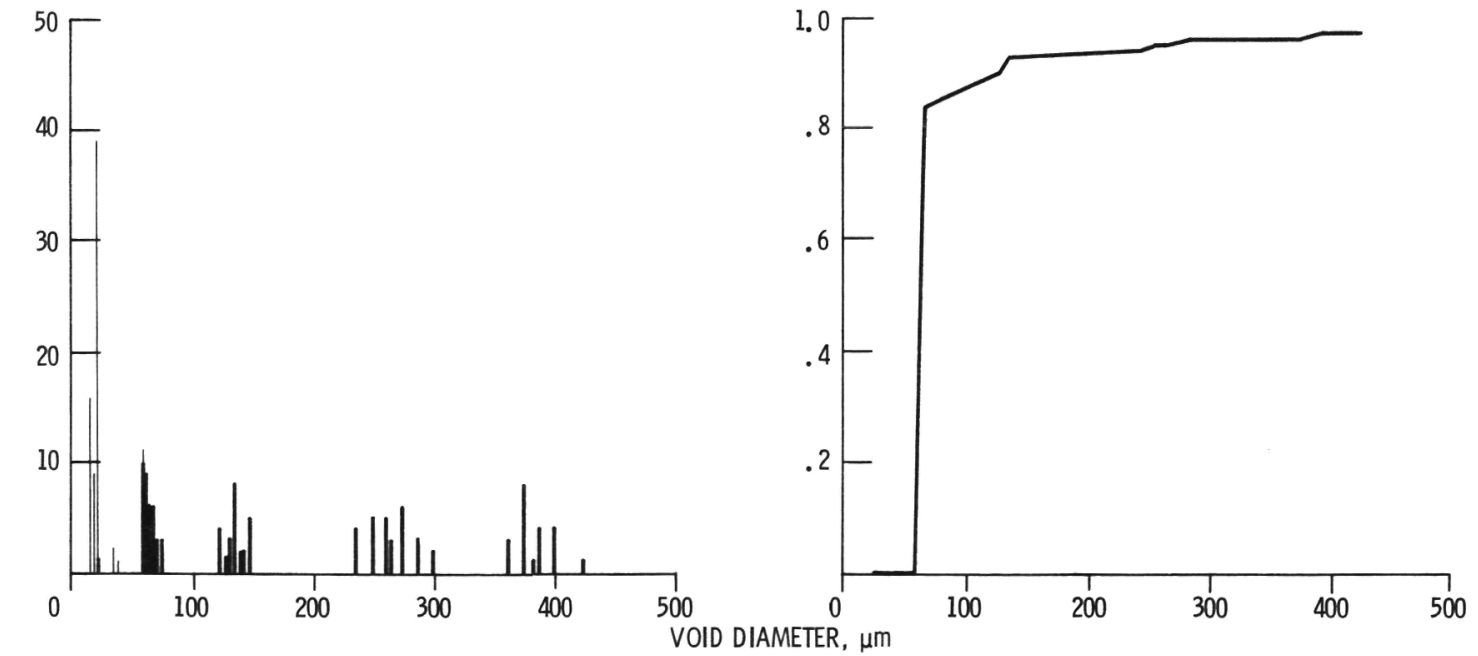

VOID DIAMETER, $\mu \mathrm{m}$

(f) Depth, 200 to $300 \mu \mathrm{m}$.

Figure 12. - Continued. 

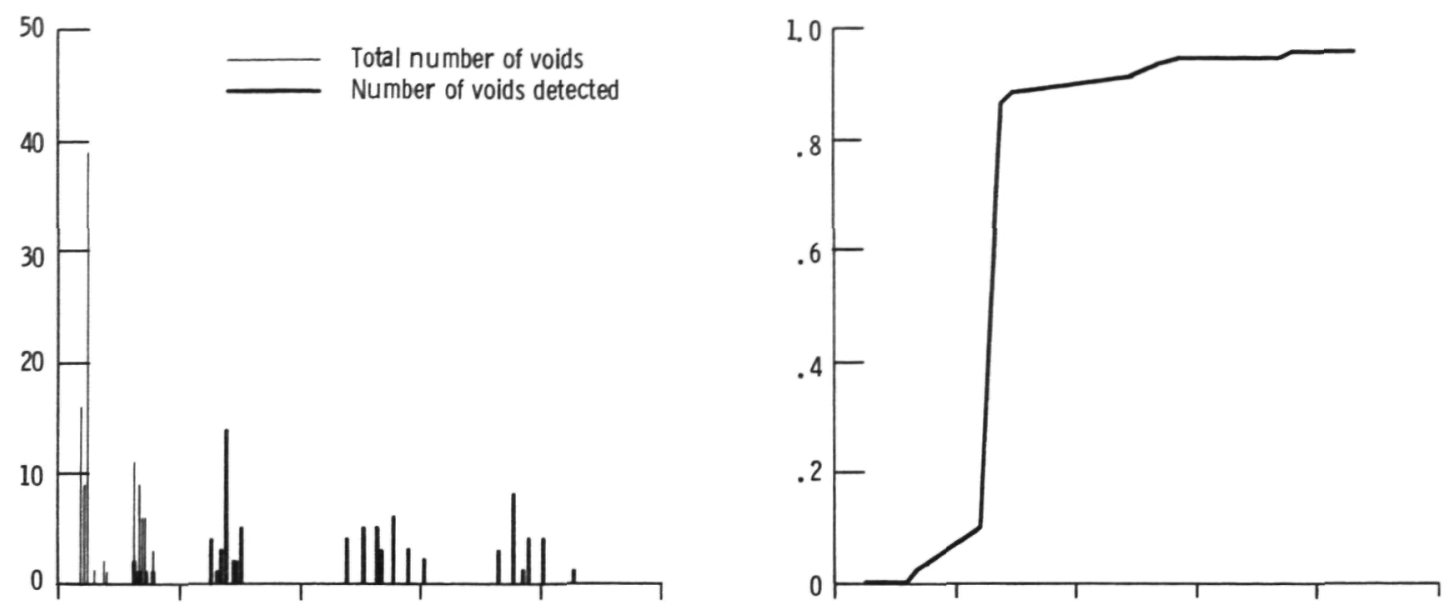

(g) Depth, 300 to $400 \mu \mathrm{m}$.
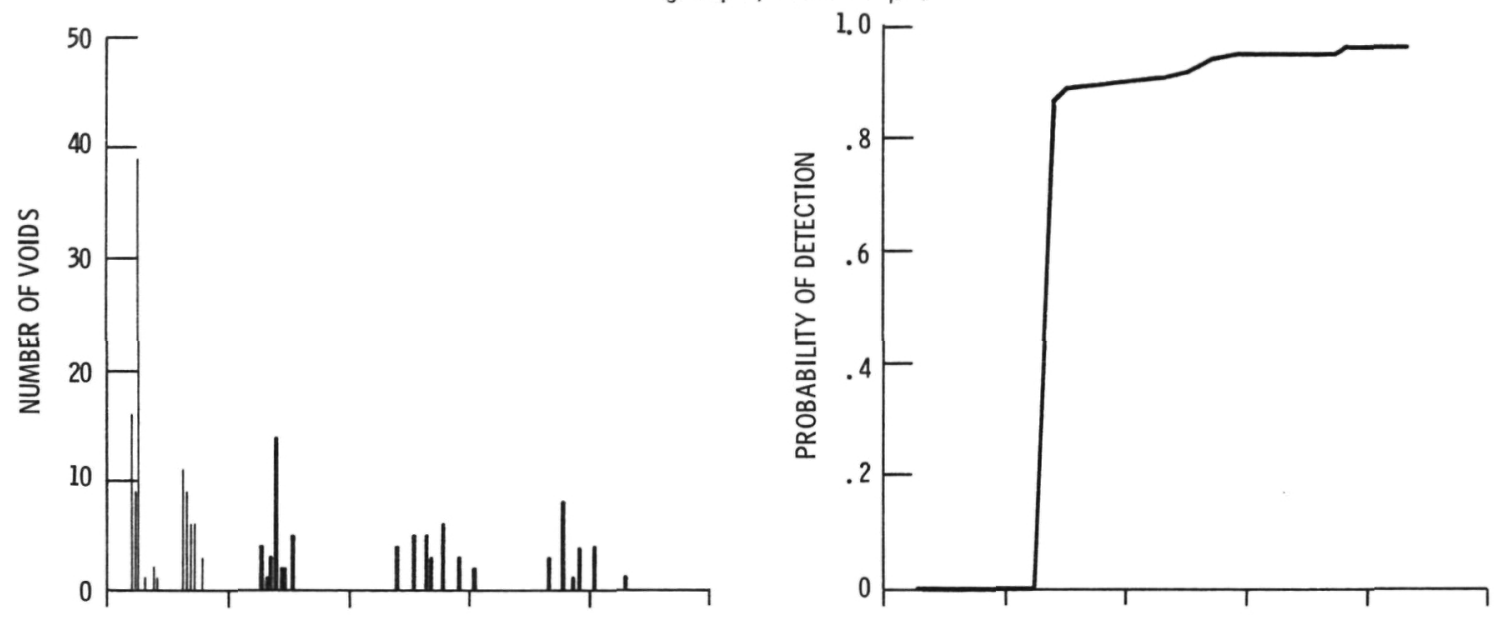

(h) Depth, 400 to $500 \mu \mathrm{m}$.
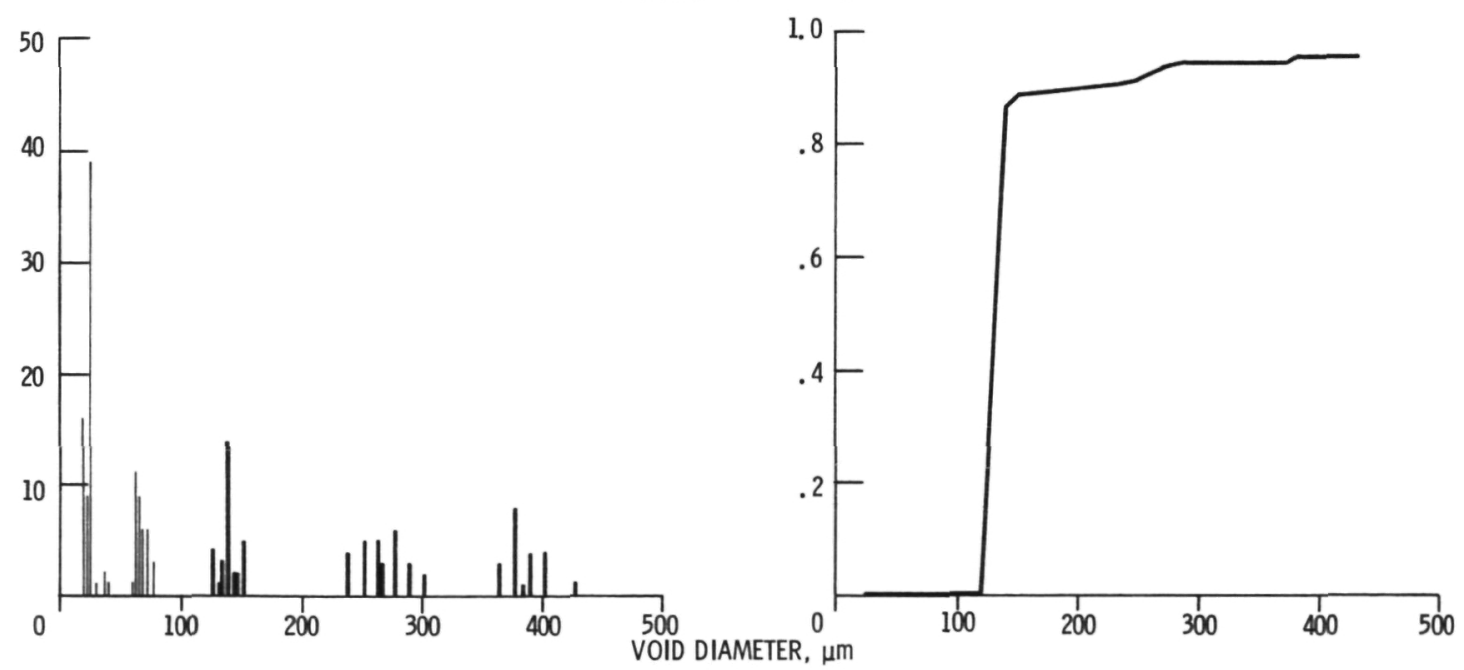

(i) Depth, 500 to $600 \mu \mathrm{m}$.

Figure 12. - Continued. 

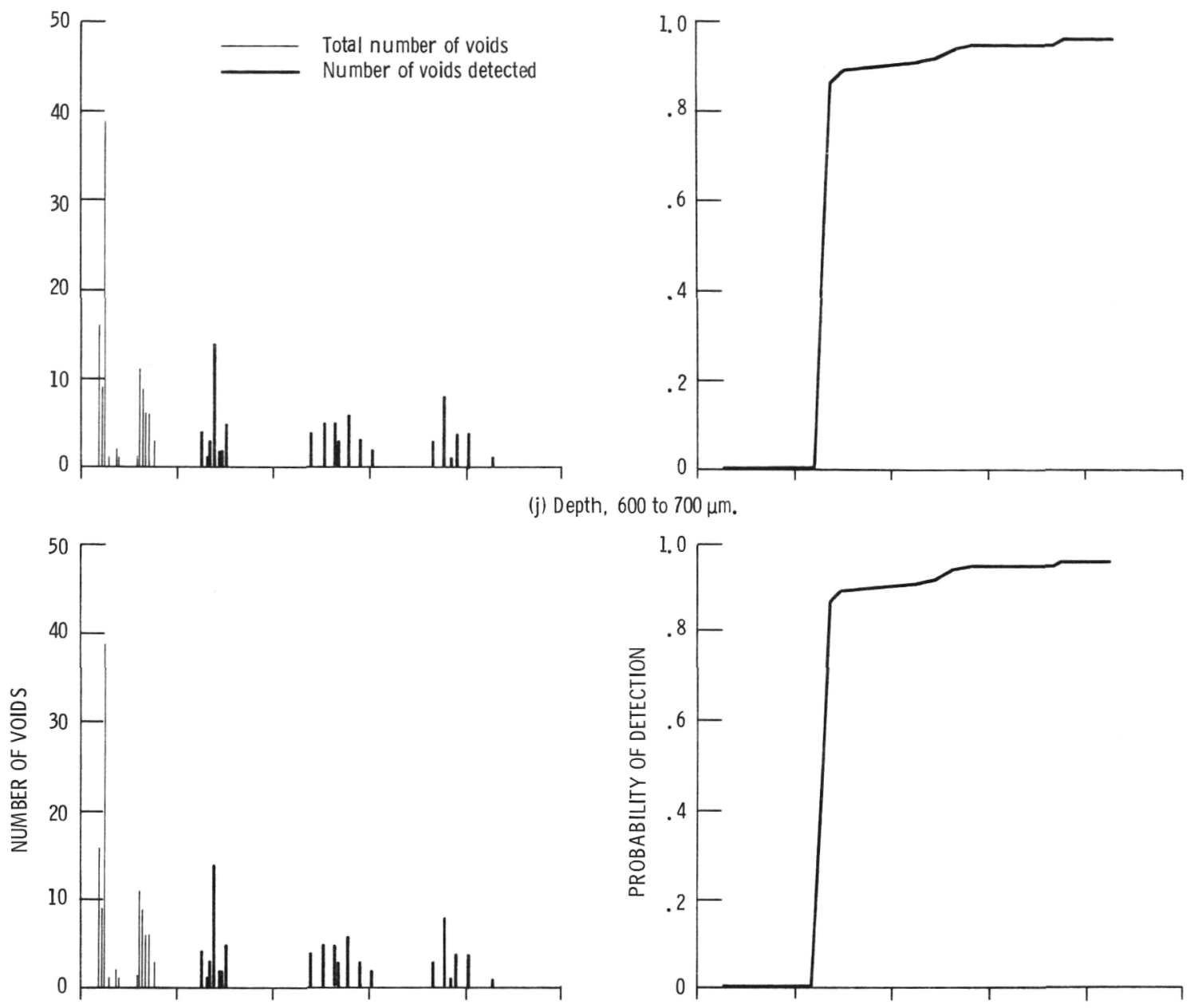

(k) Depth, 700 to $800 \mu \mathrm{m}$.
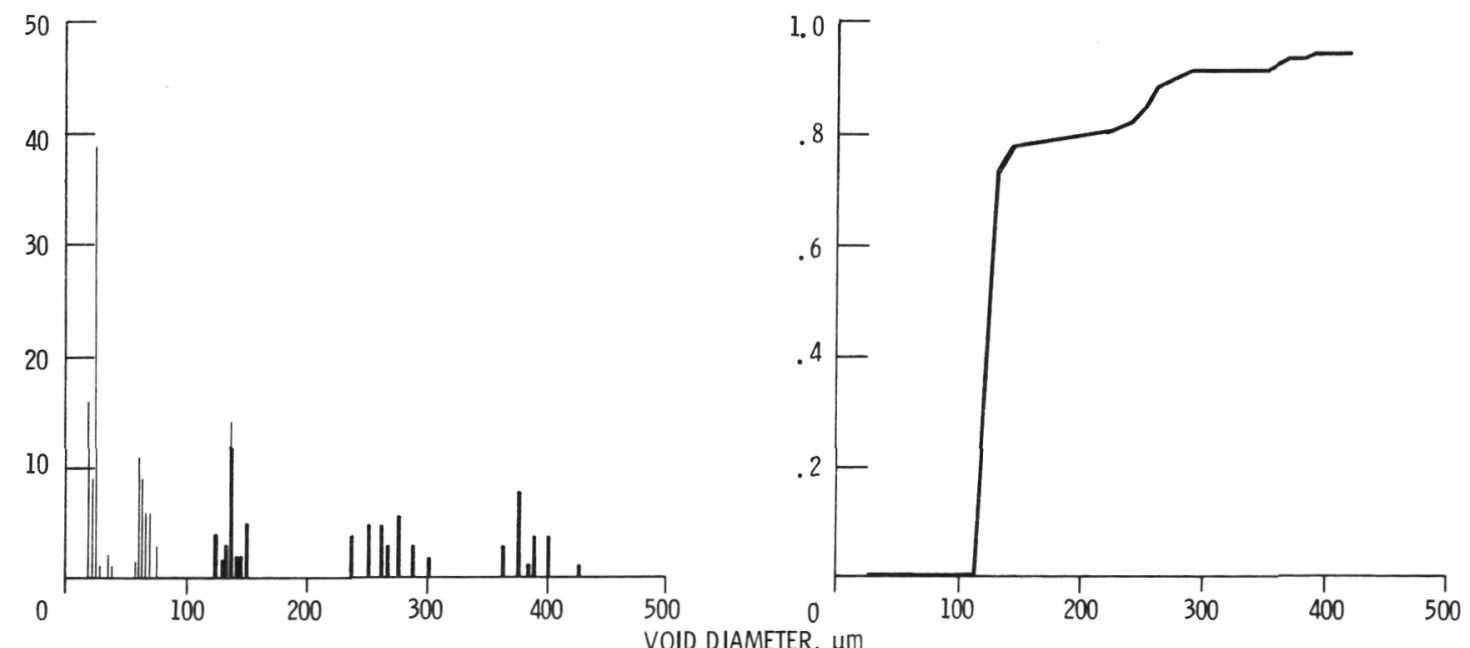

(I) Depth, 800 to $900 \mu \mathrm{m}$.

Figure 12.- Continued. 

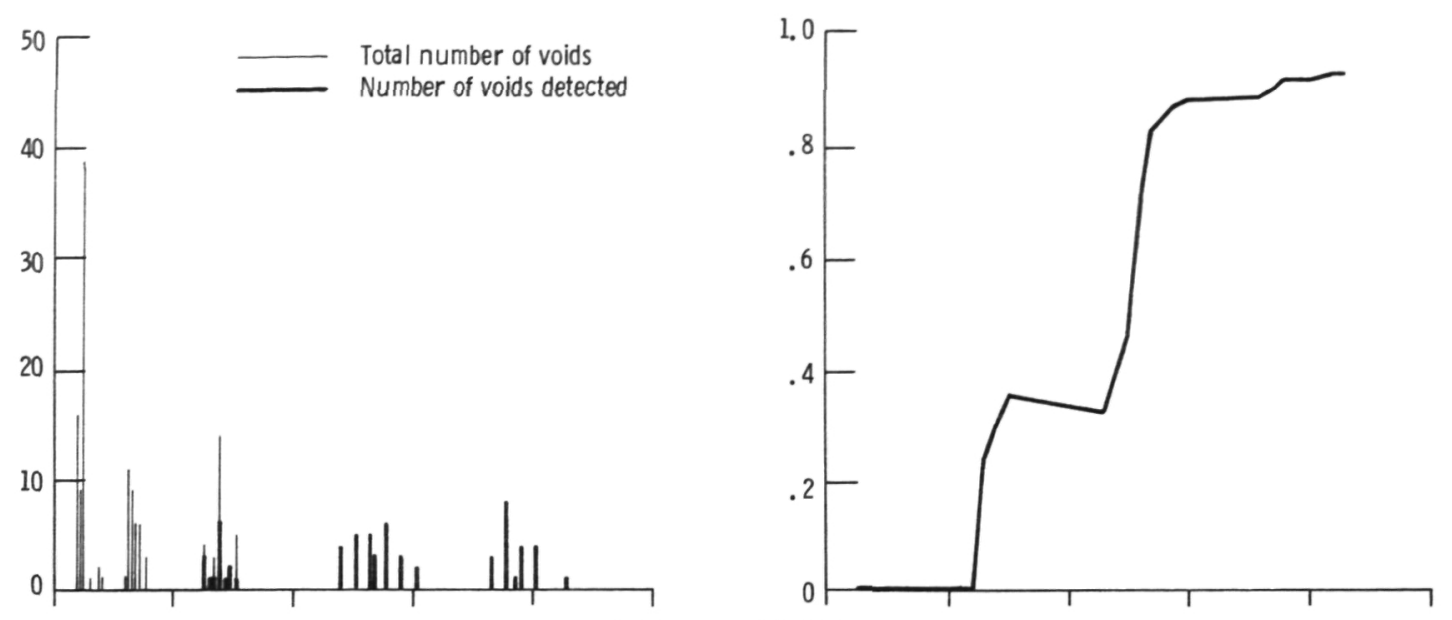

(m) Depth, 900 to $1000 \mu \mathrm{m}$.
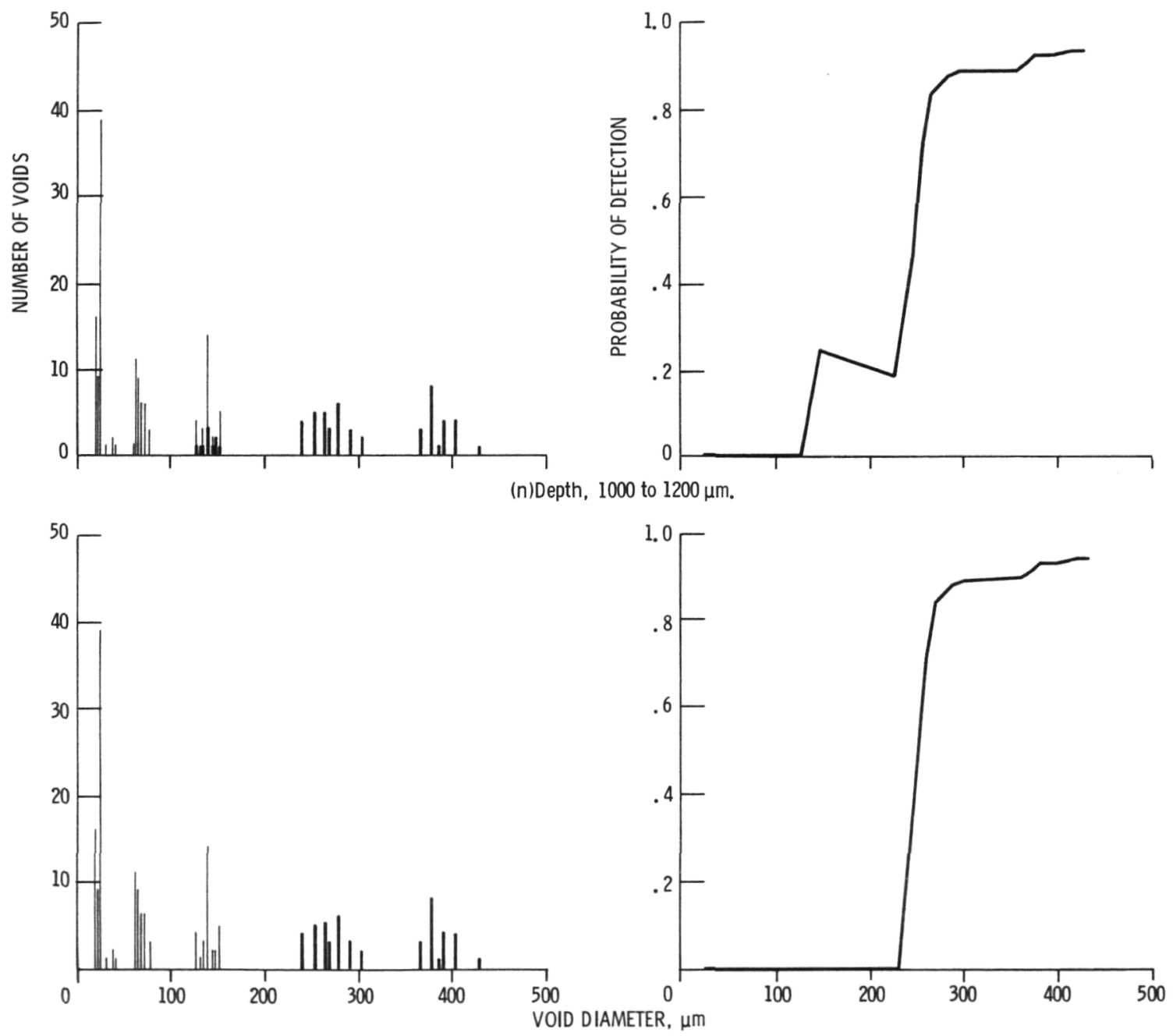

(0) Depth, 1200 to $1400 \mu \mathrm{m}$.

Figure 12. - Continued. 

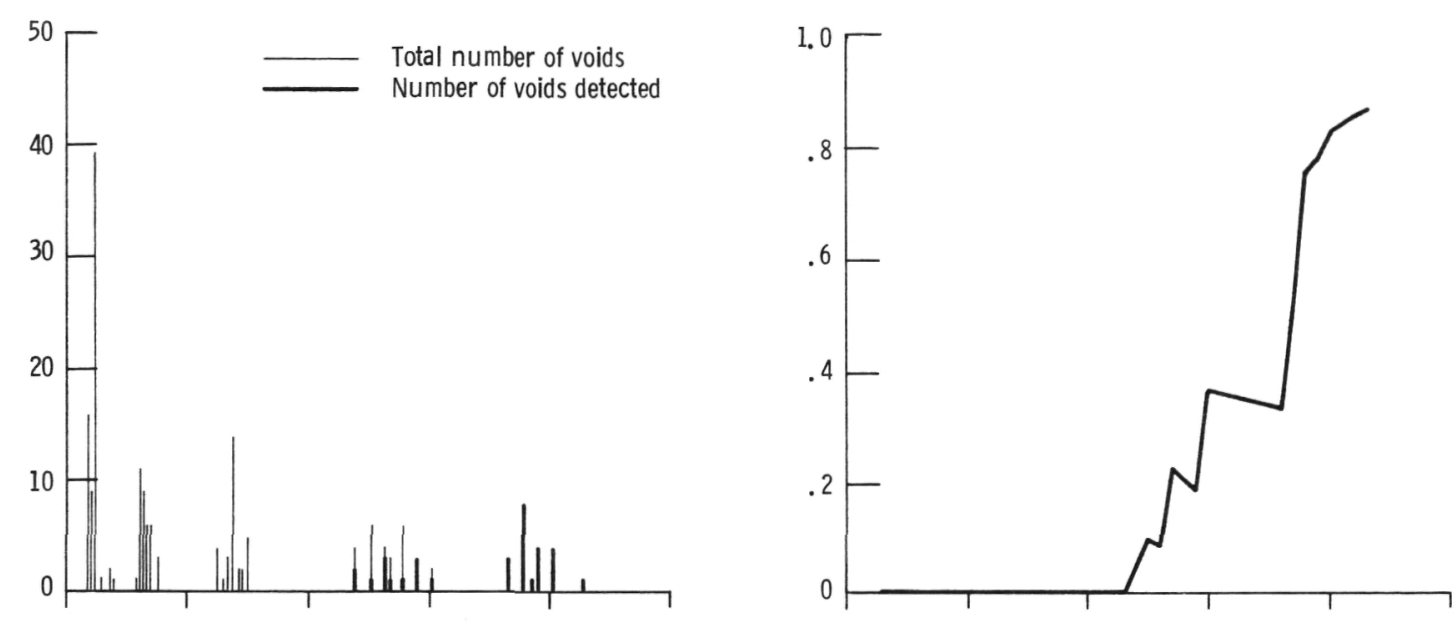

(p) Depth, 1400 to $1600 \mu \mathrm{m}$.
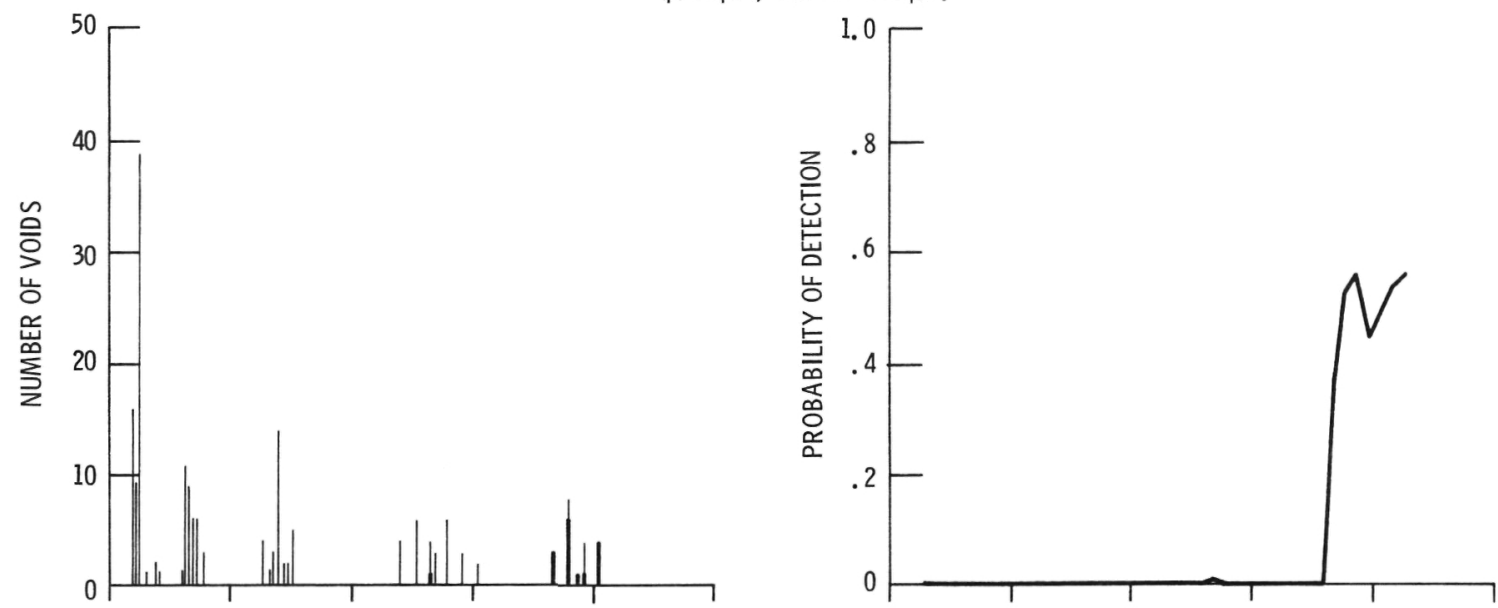

(q) Depth, 1600 to $1800 \mu \mathrm{m}$.
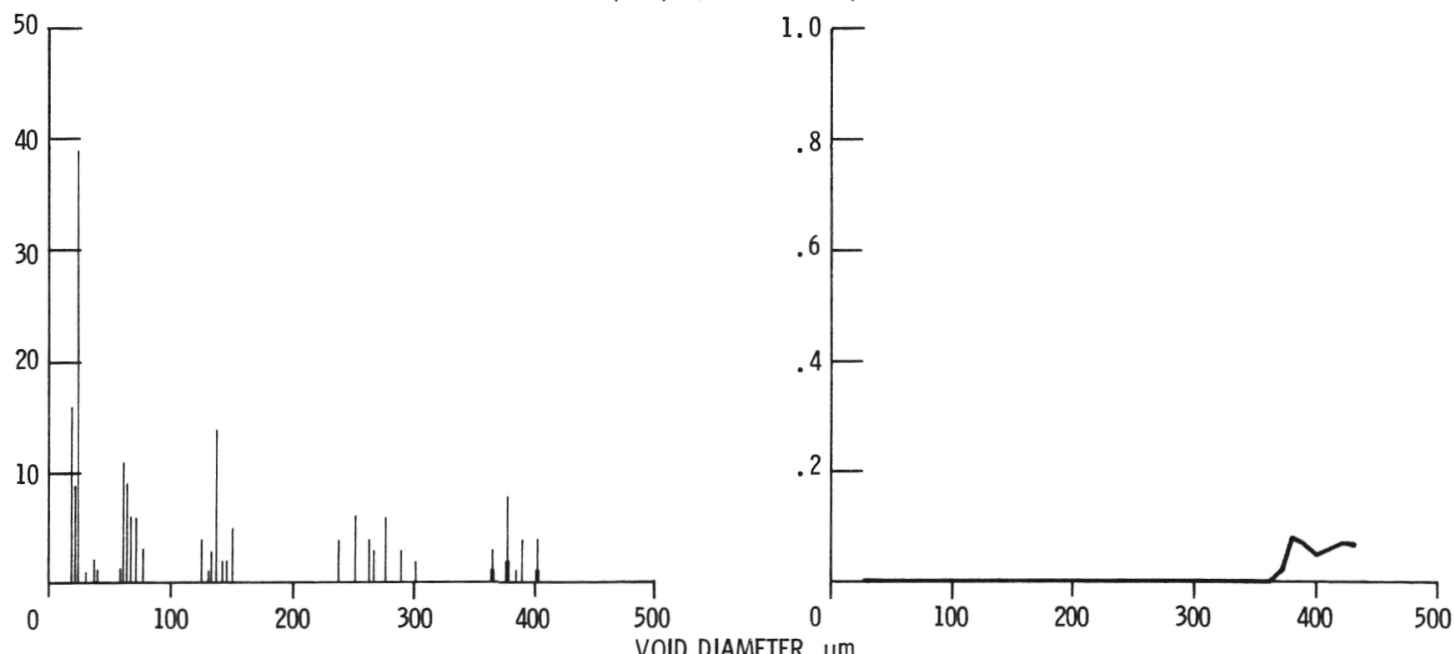

(r) Depth, 1800 to $2000 \mu \mathrm{m}$.

Figure 12. - Concluded. 

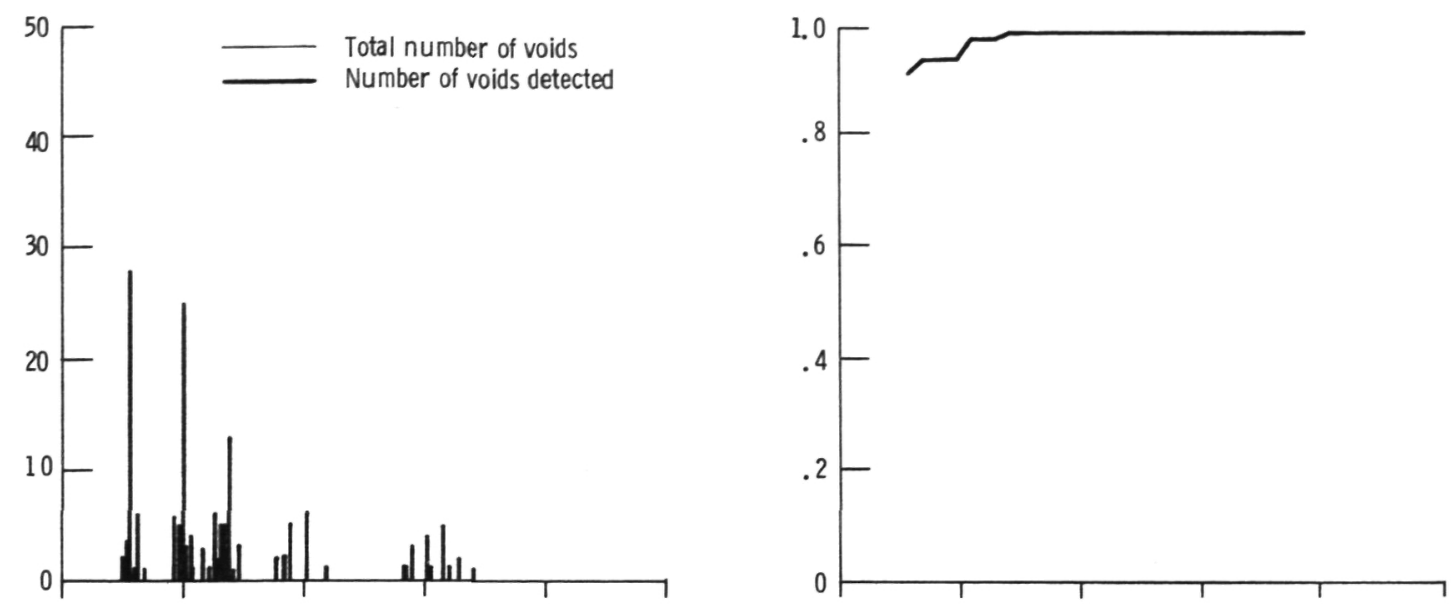

(a) Depth, 0 to $25 \mu \mathrm{m}$.
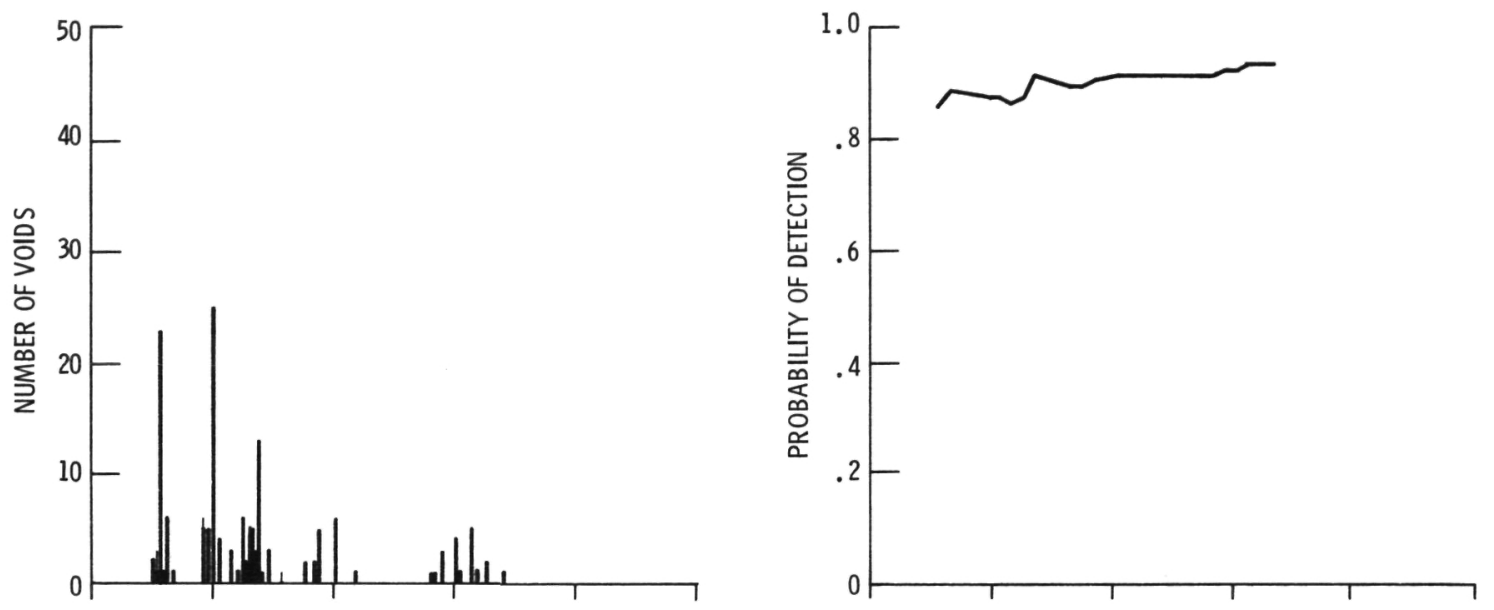

(b) Depth, 25 to $50 \mu \mathrm{m}$.
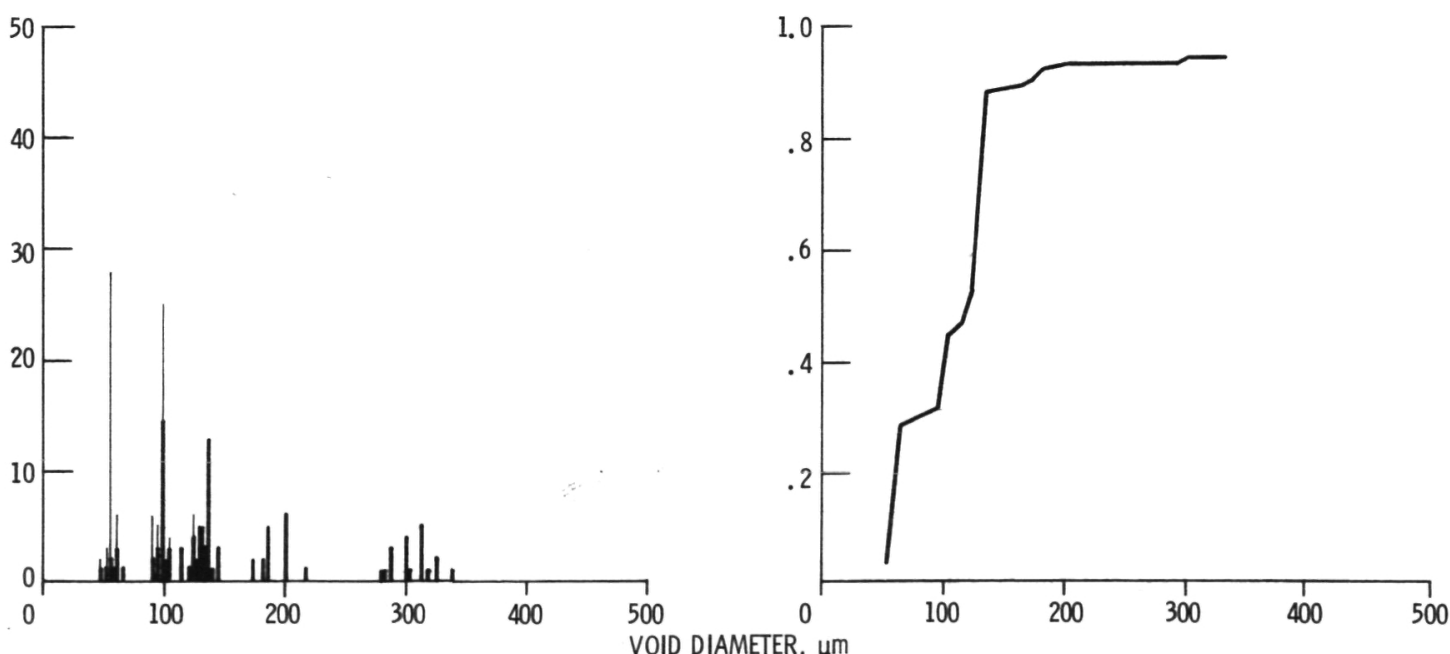

VOID DIAMETER, $\mu \mathrm{m}$

(c) Depth, 50 to $100 \mu \mathrm{m}$.

Figure 13. - Detectability data and probability of detection for seeded voids positioned below laser-scanned surface in sintered silicorr carbide specimens. Probability calculated at 0.95 confidence level. 

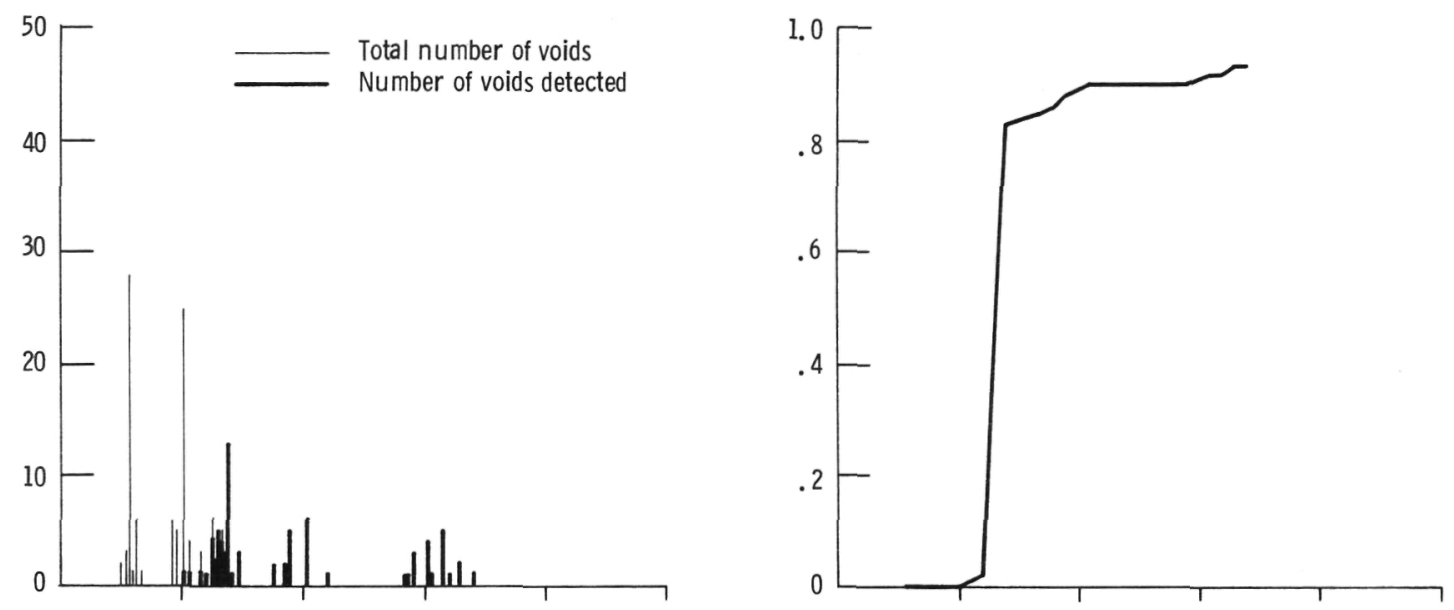

(d) Depth, 100 to $150 \mu \mathrm{m}$.
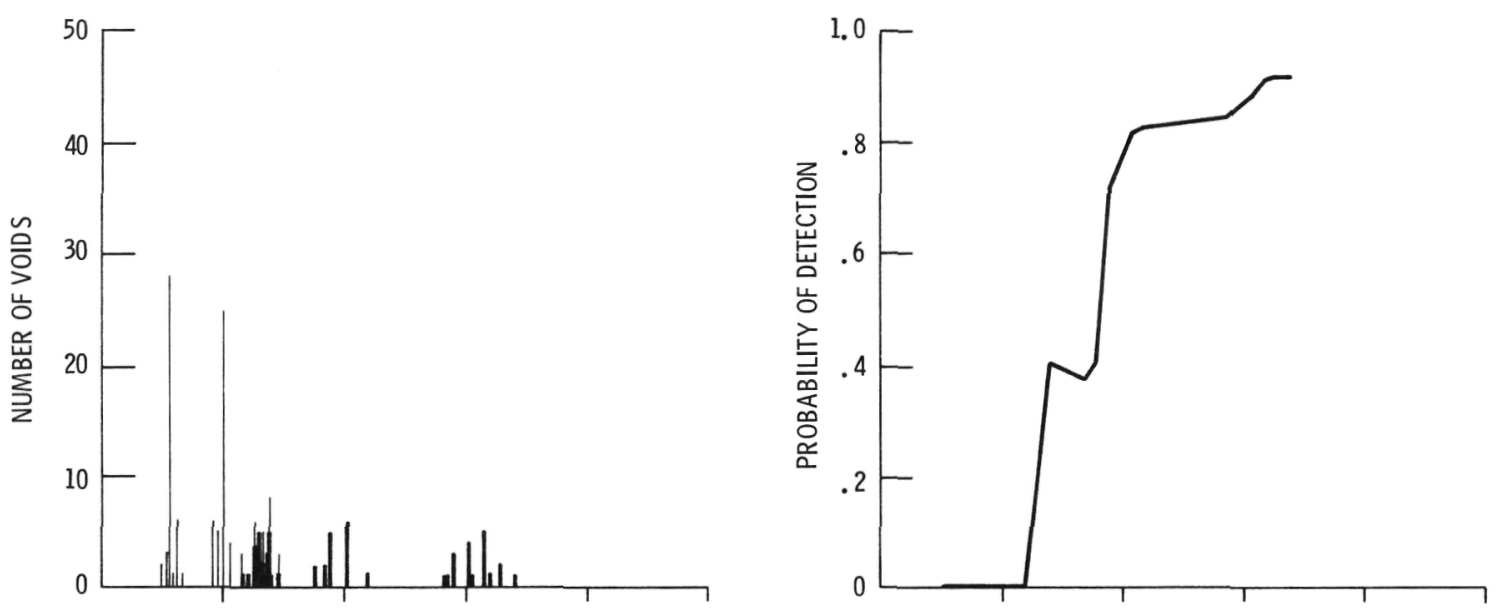

(e) Depth, 150 to $200 \mu \mathrm{m}$.
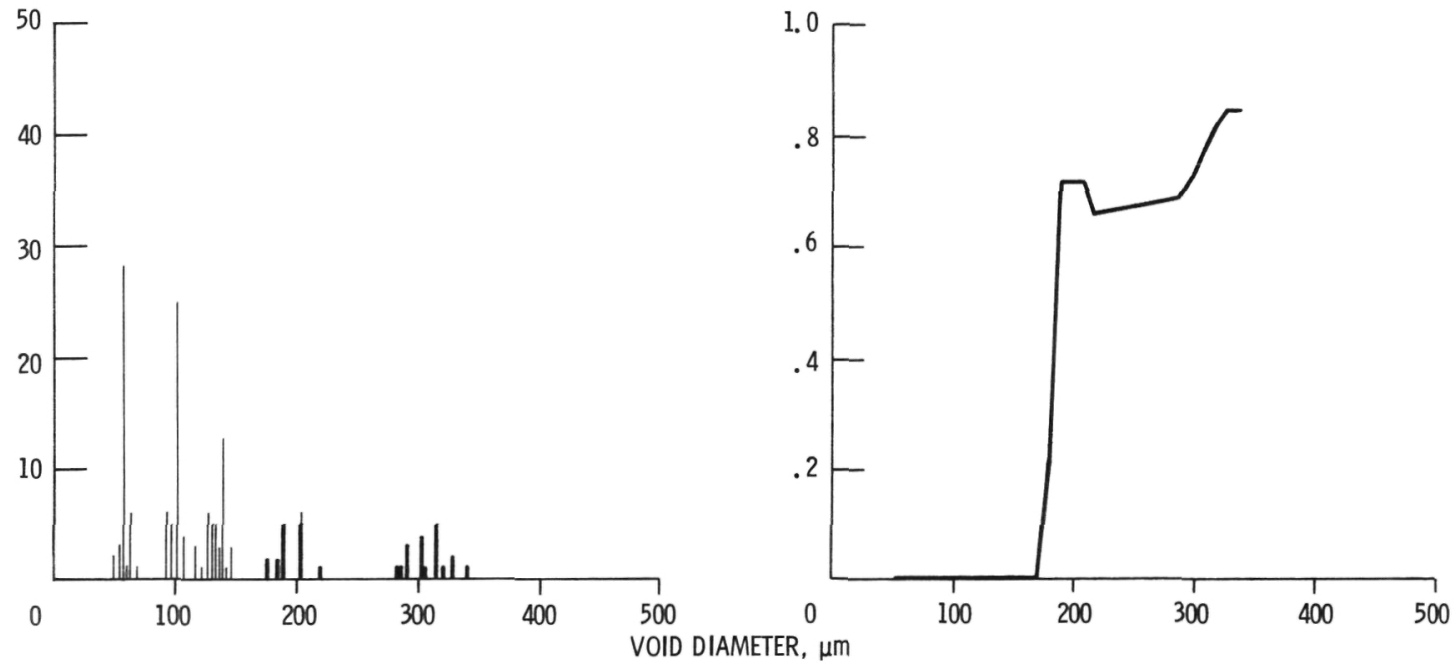

(f) Depth, 200 to $300 \mu \mathrm{m}$.

Figure 13. - Continued. 

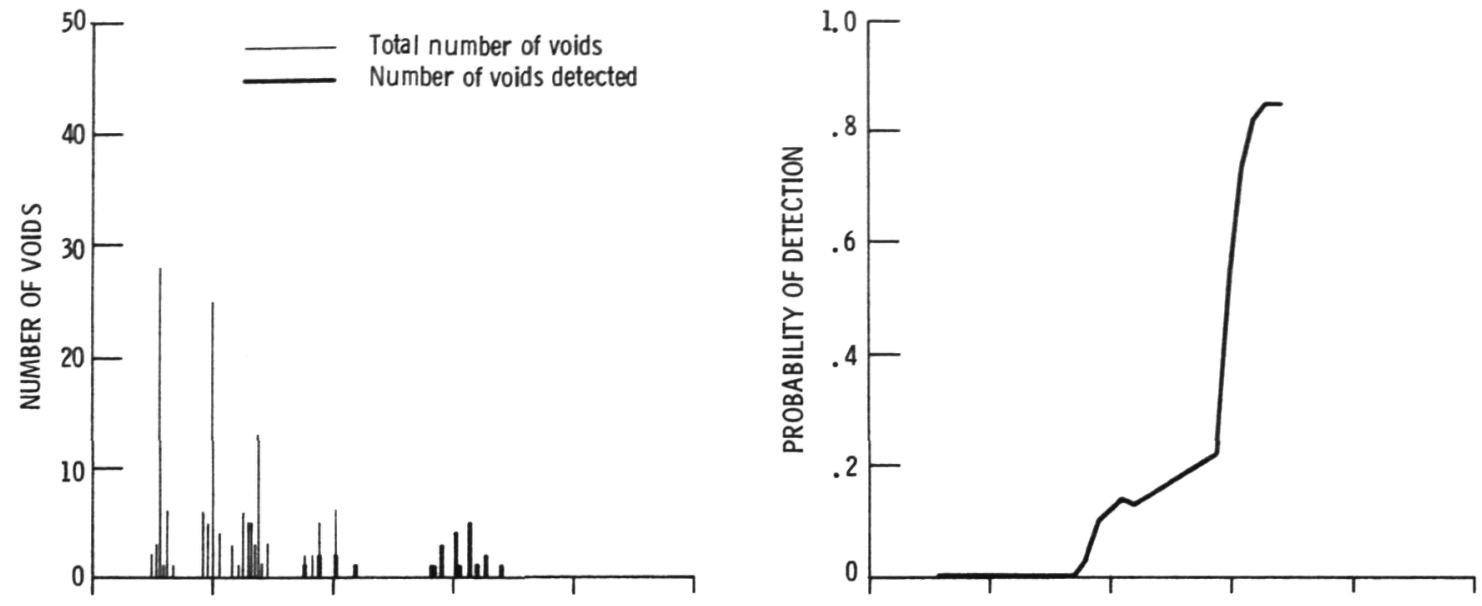

(g) Depth, 300 to $400 \mu \mathrm{m}$.
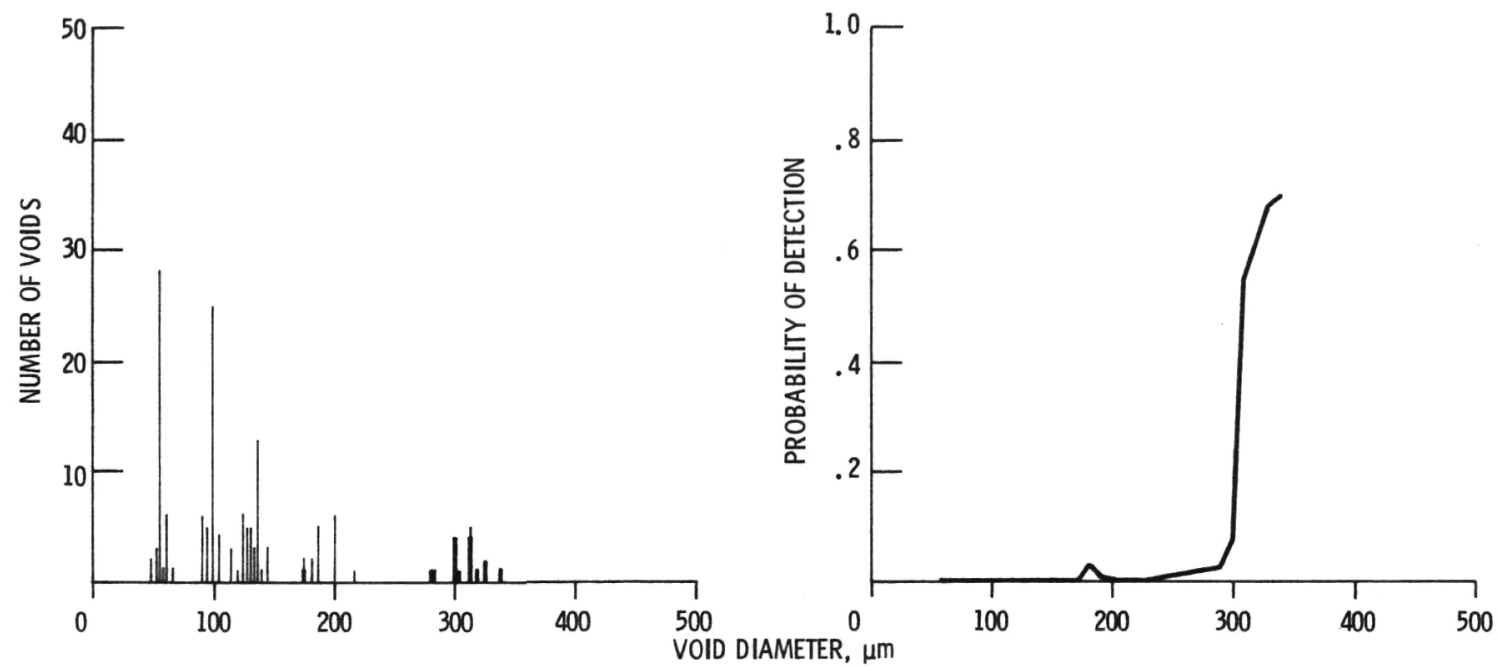

(h) Depth, 400 to $500 \mu \mathrm{m}$.

Figure 13. - Continued. 

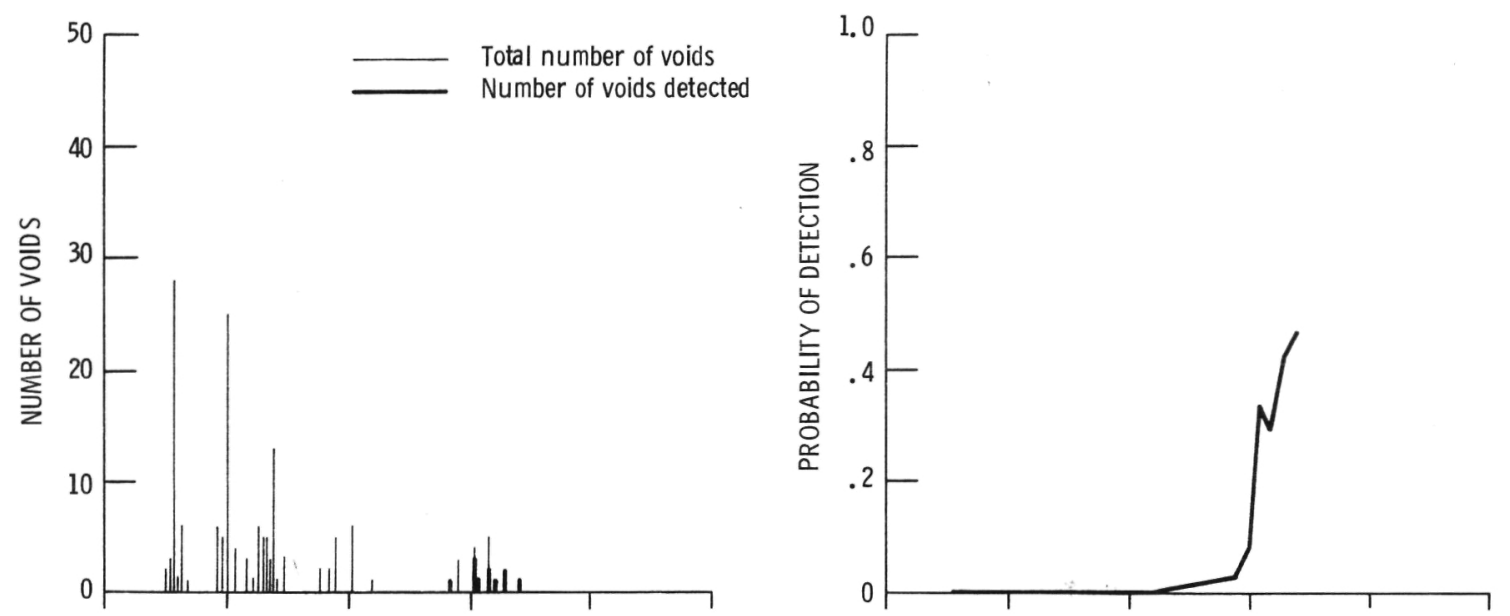

(i) Depth, 500 to $600 \mu \mathrm{m}$.
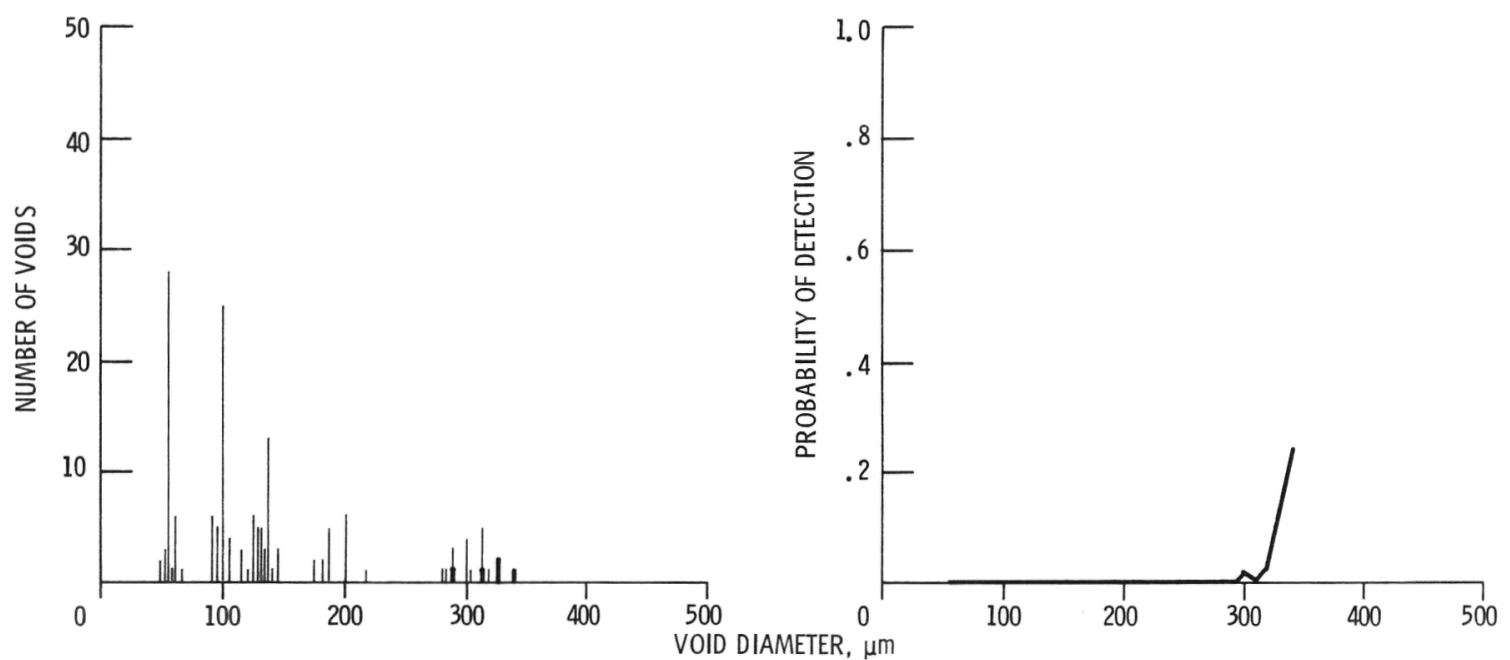

(j) Depth, 600 to $700 \mu \mathrm{m}$.

Figure 13. - Concluded, 


\begin{tabular}{|c|c|c|c|}
\hline $\begin{array}{l}\text { 1. Report No. } \\
\text { NASA TM-87222 }\end{array}$ & 2. Government Accession No. & \multicolumn{2}{|c|}{ 3. Recipient's Catalog No. } \\
\hline \multirow{3}{*}{\multicolumn{2}{|c|}{$\begin{array}{l}\text { 4. Title and Subtitle } \\
\text { Reliability of Scanning Laser Acoustic Microscopy } \\
\text { for Detecting Internal Voids in Structural Ceramics }\end{array}$}} & \multirow{2}{*}{\multicolumn{2}{|c|}{ 5. Report Date }} \\
\hline & & & \\
\hline & & \multicolumn{2}{|c|}{$\begin{array}{l}\text { 6. Performing Organization Code } \\
533-05\end{array}$} \\
\hline \multirow{3}{*}{\multicolumn{2}{|c|}{$\begin{array}{l}\text { 7. Author(s) } \\
\text { Don J. Roth and George Y. Baaklini }\end{array}$}} & \multirow{2}{*}{\multicolumn{2}{|c|}{$\begin{array}{l}\text { 8. Performing Organization Report No. } \\
\text { E-2864 }\end{array}$}} \\
\hline & & & \\
\hline & & \multicolumn{2}{|l|}{ 10. Work Unit No. } \\
\hline \multirow{3}{*}{\multicolumn{2}{|c|}{$\begin{array}{l}\text { 9. Performing Organization Name and Address } \\
\text { National Aeronautics and Space Administration } \\
\text { Lewis Research Center } \\
\text { Cleveland, Ohio } 44135\end{array}$}} & \multirow{2}{*}{\multicolumn{2}{|c|}{ 11. Contract or Grant No. }} \\
\hline & & & \\
\hline \multirow{2}{*}{\multicolumn{2}{|c|}{$\begin{array}{l}\text { 12. Sponsoring Agency Name and Address } \\
\text { National Aeronautics and Space Administration } \\
\text { Washington, D.C. } 20546\end{array}$}} & \multicolumn{2}{|c|}{$\begin{array}{l}\text { 13. Type of Report and Period Covered } \\
\text { Technical Memorandum }\end{array}$} \\
\hline & & \multicolumn{2}{|c|}{ 14. Sponsoring Agency Code } \\
\hline \multicolumn{4}{|c|}{$\begin{array}{l}\text { 15. Supplementary Notes } \\
\text { Prepared for the Tenth Annual Conference on Composites and Advanced Ceramic } \\
\text { Materials, sponsored by the American Ceramic Society, Cocoa Beach, Florida, } \\
\text { January 19-22, 1986. Don J. Roth, NASA Lewis Research Center; George Y. } \\
\text { Baaklini, Cleveland State University, Cleveland, Ohio and NASA Resident Research } \\
\text { Associate. }\end{array}$} \\
\hline \multicolumn{4}{|c|}{ 16. Abstract } \\
\hline \multicolumn{4}{|c|}{$\begin{array}{l}\text { The reliability of } 100 \mathrm{MHz} \text { scanning laser acoustic microscopy (SLAM) for detect- } \\
\text { ing internal voids in sintered specimens of silicon nitride and silicon carbide } \\
\text { was evaluated. The specimens contained artificially implanted voids and were } \\
\text { surface ground. The voids ranged from } 20 \text { to } 430 \mu m \text { in diameter and were posi- } \\
\text { tioned at depths ranging up to } 2 \mathrm{~mm} \text { below the specimen surface. Detection prob- } \\
\text { ability of } 0.90 \text { at a } 0.95 \text { confidence level was determined as a function of } \\
\text { material, void diameter, and void depth. The statistical results presented for } \\
\text { void detectability indicate some of the strengths and limitations of SLAM as a } \\
\text { nondestructive evaluation technique for structural ceramics. }\end{array}$} \\
\hline \multicolumn{2}{|c|}{$\begin{array}{l}\text { 17. Key Words (Suggested by Author(s)) } \\
\text { Nondestructive testing; Ceramics; } \\
\text { Acoustic microscopy; Uitrasonics }\end{array}$} & \multicolumn{2}{|c|}{$\begin{array}{l}\text { 18. Distribution Statement } \\
\text { Unclassified - unlimited } \\
\text { STAR Category } 38\end{array}$} \\
\hline $\begin{array}{l}\text { 19. Sécurity Classif. (of this report) } \\
\text { Unc lass if ied }\end{array}$ & $\begin{array}{l}\text { 0. Security Classif. (of this page) } \\
\text { Unc las s if ied }\end{array}$ & 21. No. of pages & 22. Price* \\
\hline
\end{tabular}

*For sale by the National Technical Information Service, Springfield, Virginia 22161 
National Aeronautics and

Space Administration

Lewis Research Center

Cleveland. Ohio 44135

Official Business

Penalty for Private Use $\$ 300$
SECOND CLASS MAIL

ADDRESS CORRECTION REQUESTED

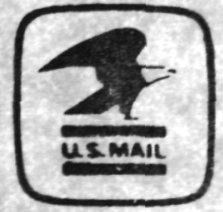

Postage and Fees Paid National Aeronautics and Space Administration NASA-451 